\title{
Variational assimilation of land surface temperature within the ORCHIDEE Land Surface Model Version 1.2.6
}

\author{
Hector Simon Benavides Pinjosovsky ${ }^{1,5,6}$, Sylvie Thiria ${ }^{1,3}$, Catherine Ottlé ${ }^{5}$, Julien Brajard ${ }^{1,2}$, Fouad Badran ${ }^{4}$, and \\ Pascal Maugis 5 \\ ${ }^{1}$ Sorbonne University, UPMC Univ Paris 06 CNRS-IRD-MNHN, LOCEAN Laboratory 4 place Jussieu,75005 Paris, France \\ ${ }^{2}$ Inria Paris, 75012 Paris, France \\ ${ }^{3}$ UVSQ, 78035 Versailles, France \\ ${ }^{4}$ Laboratoire CEDRIC, Conservatoire National des Arts et Métiers, 292, rue Saint Martin, 75003 Paris, France \\ ${ }^{5}$ Laboratoire des Sciences du Climat et de l'Environnement (LSCE), UMR 8212, CNRS-CEA-UVSQ, Orme des Merisiers, \\ 91191 Gif-sur-Yvette, France \\ ${ }^{6}$ CLIMMOD Engineering, Orsay, France
}

Correspondence to: Hector Simon Benavides Pinjosovsky (spinjosovsky@gmail.com)

and Sylvie Thiria (sylvie.thiria@locean-ipsl.upmc.fr)

Received: 23 March 2016 - Published in Geosci. Model Dev. Discuss.: 14 April 2016

Revised: 7 November 2016 - Accepted: 16 November 2016 - Published: 6 January 2017

\begin{abstract}
The SECHIBA module of the ORCHIDEE land surface model describes the exchanges of water and energy between the surface and the atmosphere. In the present paper, the adjoint semi-generator software called YAO was used as a framework to implement a 4D-VAR assimilation scheme of observations in SECHIBA. The objective was to deliver the adjoint model of SECHIBA (SECHIBA-YAO) obtained with YAO to provide an opportunity for scientists and end users to perform their own assimilation. SECHIBA-YAO allows the control of the 11 most influential internal parameters of the soil water content, by observing the land surface temperature or remote sensing data such as the brightness temperature. The paper presents the fundamental principles of the 4D-VAR assimilation, the semi-generator software YAO and a large number of experiments showing the accuracy of the adjoint code in different conditions (sites, PFTs, seasons). In addition, a distributed version is available in the case for which only the land surface temperature is observed.
\end{abstract}

\section{Introduction}

Land surface models (LSMs) simulate the interactions between the atmosphere and the land surface, which directly influence the exchange of water, energy and carbon with the atmosphere. They are important tools for understanding the main interaction and feedback processes simulating the present climate and making predictions of future climate evolution (Harrison et al., 2009). Such predictions are subject to considerable uncertainties, which are related to the difficulty in modeling the highly complex physics with a limited set of equations that does not account for all the interacting processes (Pipunic et al., 2008; Ghent et al., 2011). Understanding these uncertainties is important in order to obtain more realistic simulations.

A key challenge of a dynamical model is to adjust the output of the model considering an appropriate source of information. One source of information can be given by measurements (or more generally observations) that contribute to the understanding of the system evolution (Lahoz et al., 2010). Data assimilation merges these observations with the dynamical model in order to obtain a more accurate estimate of the current and future states of the system, given the uncertainties of the model and of the observations. Two basic methodologies can be used for that purpose: the sequential approach (Evensen, 2003), based on the statistical estimation theory of the Kalman filter, and the variational approach, the so-called 4D-VAR (Le Dimet et al., 1986), built from the optimal control theory (Robert et al., 2007). It can be proven that both approaches provide the same solution at the end of the assim- 
ilation period, for Gaussian errors (not correlated in time) and linear models. This property does not stand if the processes under study are nonlinear. The main advantage of 4D-VAR comes from its integration in time achieved during the assimilation of the observations, giving rise to a global trajectory of the model optimized over the assimilation time window.

Variational data assimilation has been widely used in land surface applications. The assimilation of land surface temperature (LST) is suitable for an extensive range of environmental problems. As mentioned in Ridler et al. (2012), LST is an excellent candidate for model optimization since it is a solution of the coupled energy and water budgets, and permits one to constrain parameters related to evapotranspiration and indirectly to soil water content.

Castelli et al. (1999) expose a variational data assimilation approach, including surface energy balance in the estimation procedure as a physical constraint (based on adjoint techniques). The authors worked with satellite data and directly assimilated soil skin temperatures. They concluded that constraining the model with such observations improves model flux estimates, with respect to available measurements. Huang et al. (2003) developed a one-dimensional land data assimilation scheme based on an ensemble Kalman filter, used to improve the estimation of the land surface temperature profile. They demonstrated that the assimilation of LST into land surface models is a practical and effective way to improve the estimation of land surface state variables and fluxes.

Reichle et al. (2010) performed the assimilation of satellite-derived skin temperature observations using an ensemble-based, offline land data assimilation system. Results suggest that the retrieved fluxes provide modest but statistically significant improvements. However, these authors noted strong biases between LST estimates from in situ observations, land modeling, and satellite retrievals that vary with season and time of the day. They highlighted the importance of taking these biases into account; otherwise, large errors in surface flux estimates can result.

Ghent et al. (2011) investigated the impacts of data assimilation on terrestrial feedbacks of the climate system. Assimilation of LST helped to constrain simulations of soil moisture and surface heat fluxes. Ridler et al. (2012) tested the effectiveness of using satellite estimates of radiometric surface temperatures and surface soil moisture to calibrate a soilvegetation-atmosphere transfer (SVAT) model, based on error minimization of temperature and soil moisture model outputs. Flux simulations were improved when the model is calibrated against in situ surface temperature and surface soil moisture versus satellite estimates of the same fluxes.

Bateni et al. (2013) employed the full heat diffusion equation to perform a variational data assimilation. Deviation terms of the evaporation fraction and a scale coefficient were added as penalization terms in the cost function. A weak constraint was applied to data assimilation with model uncertainty, accounting in this way for model errors. The cost function associated with this experiment contains a term that penalizes the deviation from prior values. When assimilating LST into the model, the authors proved that the heat diffusion coefficients are strongly sensitive. As a conclusion, it can be seen that the assimilation of LST can improve the model simulated flows.

In the present study, we focused on the SECHIBA module (Ducoudré et al., 1993), which is part of the ORCHIDEE land surface model dedicated to the resolution of the surface energy and water budgets. Our objective was to test the ability of 4D-VAR to estimate a set of its inner parameters. A dedicated software (called SECHIBA-YAO) was developed by using the adjoint semi-generator software called YAO developed at LOCEAN-IPSL (Nardi et al., 2009). YAO serves as a framework to design and implement dynamical models, helping to generate the adjoint of the model, which permits one to compute the model gradients. SECHIBA-YAO provides an opportunity to control the most influent internal parameters of SECHIBA by assimilating LST (land surface temperature) observations. At a given location and for specific soil and climate conditions, twin experiments of assimilation have been executed. These twin experiments conducted on actual sites were used to demonstrate the accuracy and usefulness of the code and the potential of 4D-VAR when dealing with LST assimilation.

This paper is structured as follows. In Sect. 2, model and data used to illustrate the capabilities of the SECHIBA-YAO are detailed. In Sect. 3, fundamentals of variational data assimilation are presented. In addition, principles of YAO and of its associated modular graph formalism are shown. The principle of the computation of the adjoint with YAO is provided. The implementation of SECHIBA-YAO and the details of the experiments that prove the efficiency of the 4DVAR assimilation are also given in Sect. 3. Sensitivity experiments and simple twin experiments at two FLUXNET locations are presented in Sect. 4. These experiments illustrate the convenience of YAO to optimize control parameters. Section 5 consists in a discussion and a conclusion. Finally, the specificities of the distributed software are given in Sect. 6 .

\section{Models and data}

ORCHIDEE is a land surface model developed at the Institut Pierre Simon Laplace (IPSL) in France. ORCHIDEE is a mechanistic dynamic global vegetation model (Krinner et al., 2005) representing the continental biosphere and its different biophysical processes. It is part of the IPSL earth system model (Dufresne et al., 2013) and is composed of three modules: SECHIBA, STOMATE and LPJ. The version used in this work corresponds to version 1.2.6, released on 22 April 2010. SECHIBA computes the water and energy budgets at the biosphere-atmosphere interface, as well as the gross primary production (GPP); STOMATE (Friedlingstein et al., 1999) is a biogeochemical model which represents the 
processes related to the carbon cycle, such as carbon dynamics, the allocation of photosynthesis respiration and growth maintenance, heterotrophic respiration and phenology, and finally, LPJ (Sitch et al., 2003) models the global dynamics of the vegetation, interspecific competition for sunlight as well as fire occurrence. ORCHIDEE has different timescales: 30 min for energy and matter, 1 day for carbon processes and 1 year for species competition processes. The full description of ORCHIDEE can be found in Ducoudré et al. (1993), Krinner et al. (2005), d'Orgeval et al. (2006), and Kuppel et al. (2012). In the present study, ORCHIDEE version 1.9 is used in a grid-point mode (at a given location), forced by the corresponding local half-hourly gap-filled meteorological measurements obtained at the flux towers. In this study, only the SECHIBA module is considered.

In SECHIBA, the land surface is represented as a whole system composed of various fractions of vegetation types called PFTs (plant functional types). A single energy budget is performed at each grid point, but the water budget is calculated for each PFT fraction. The resulting energy and water fluxes between atmosphere, ground and the retrieved temperature represent the canopy ensemble and the soil surface. The main fluxes modeled are the net radiation $\left(R_{\mathrm{n}}\right)$, soil heat flux $(Q)$, sensible $(H)$ and latent heat (LE) fluxes between the atmosphere and the biosphere, land surface temperature (LST) and the soil water reservoir contents. Energy balance is solved once, with a subdivision only for LE in bare soil evaporation, interception and transpiration for each type of vegetation. Water balance is computed for each fraction of vegetation (plant functional type or PFT) present in the grid. The SECHIBA version used in this work models the hydrological budget based on a two-layer soil profile (Choisnel, 1977). The two soil layers represent, respectively, the surface and the total rooting zone. The soil is considered homogeneous with no sub-grid variability and a total depth of $h_{\text {tot }}=2 \mathrm{~m}$. The soil bottom layer acts like a bucket that is filled with water from the top layer. The soil is filled from top to bottom with precipitation; when evapotranspiration is higher than precipitation, water is removed from the upper reservoir. Runoff arises when the soil is saturated. SECHIBA inputs are $R_{\mathrm{lw}}$ the incoming infrared radiation; $R_{\mathrm{sw}}$ the incoming solar radiation; $P$ the total precipitation (rain and snow); $T_{\mathrm{a}}$ the air temperature; $Q_{\mathrm{a}}$ the air humidity; $P_{\mathrm{S}}$ the atmospheric pressure at the surface and $U$ the wind speed.

In the full version of SECHIBA-YAO, observations of LST or brightness temperature can be used to constrain model inner parameter or initial conditions of the model variables. However, the simulated LST is hemispheric and does not account for solar configuration and viewing angle effects. In order to compute a thermal infrared brightness temperature from LST, and neglecting the directional effects, the total energy emitted by the surface (Rad) can be computed using the following expression:

$\operatorname{Rad}=k_{\text {emis }} \varepsilon \mathrm{LST}^{4}+\left(1-\varepsilon k_{\mathrm{emis}}\right) \mathrm{LW}_{\text {down }}$.
In this equation, $\varepsilon$ is the surface emissivity, $k_{\mathrm{emis}}$ is the multiplicative factor for emissivity and $\mathrm{LW}_{\text {down }}$ is the longwave incident radiation that is an input forcing of SECHIBA. Svendsen et al. (1990) proposed a transfer function to link the surface emitted radiance towards an observed brightness temperature TB measured in the $[8,14]$ spectral band. The empirical formulation is given by the expression

$\mathrm{TB}=\left(\frac{\operatorname{Rad}-7.84}{6.7975 .10^{11}}\right)^{0.2}$.

In the following, the capabilities of the 4D-VAR are demonstrated in a series of assimilation experiments using the data provided by the FLUXNET network (Baldocchi et al., 2001). FLUXNET is a network coordinating regional and global analysis of observations from micrometeorological tower sites. The flux tower sites use eddy covariance methods (Aubinet et al., 2012) to measure the exchange of carbon dioxide $\left(\mathrm{CO}_{2}\right)$, water vapor, and energy between terrestrial ecosystems and the atmosphere. SECHIBA-YAO can be run using other data as long as the same inputs needed to operate SECHIBA are given.

Measurement towers sprang up around the world, grouped into regional networks. The data from all networks are accessible to the scientific community via the FLUXNET website (http://www.fluxdata.org). In this work, we selected two sites: Harvard Forest and Skukuza Kruger National Park; both present contrasted climate and land surface properties suitable for testing the tools developed and assessing model parameter sensitivities. Only climate measurements with the same sampling frequency $(30 \mathrm{~min})$ from both sites are used to force SECHIBA. Vegetation characteristics are prescribed and only homogeneous grids are considered. Two cases were studied with agricultural C3 (PFT 12) and bare soil (PFT 1).

\subsection{Skukuza Kruger National Park}

Located in South Africa at $25^{\circ} 1^{\prime} 11^{\prime \prime} \mathrm{S}$ and $31^{\circ} 29^{\prime} 48^{\prime \prime} \mathrm{E}$, this FLUXNET site was established in 2000. The tower overlaps two distinct savanna types and collects information about land-atmosphere interactions. The climate is subtropical-Mediterranean. The total mean annual precipitation is $650 \mathrm{~mm}$, with an altitude of $150 \mathrm{~m}$, and the mean annual temperature is $22.15^{\circ} \mathrm{C}$.

\subsection{Harvard Forest}

Located in the United States of America, on land owned by Harvard University, the station is located at $42^{\circ} 53^{\prime} 78^{\prime \prime} \mathrm{N}$ and $72^{\circ} 17^{\prime} 15^{\prime \prime} \mathrm{W}$. It was established in 1991 . The site has a temperate-continental climate with hot or warm summers and cold winters. The annual mean precipitation is $1071 \mathrm{~mm}$, the mean annual temperature is $6.62^{\circ} \mathrm{C}$ and the altitude is $340 \mathrm{~m}$. 


\section{The methodology}

\subsection{Variational assimilation}

Variational assimilation (4D-VAR) (Le Dimet et al., 1986) considers a physical phenomenon described in space and its time evolution. It thus requires the knowledge of a direct dynamical model $M$, which describes the time evolution of the physical phenomenon. $M$ computes geophysical variables, which are compared to observations. By varying some model parameters (control parameters), assimilation seeks to infer geophysical variables that are the closet to observation values (LST in the present case). The control parameters can be, as an example, initial conditions or physical parameters of $M$ leading to the computation of LST.

The basic idea is to determine the minimum of a cost function $\boldsymbol{J}$ that measures the misfits between the observations and the model estimations. Due to the complexity of this function, the solution is classically obtained by using gradient methods, which implies the use of the adjoint model of $M$. This model is derived from the equations of the direct model $M$. The adjoint model estimates changes in the control variables in response to a disturbance of the output values calculated by $M$. It is done by integrating the same model in the backward direction (e.g., time integration is from the future to the past). If observations are available, the adjoint allows one to minimize the cost function $\boldsymbol{J}$.

Formalism and notations for variational data assimilation are taken from Ide et al. (1997). $M$ represents the direct model, $\boldsymbol{x}\left(t_{0}\right)$ is the initial state of the model and $\boldsymbol{k}$ represents the vector of the inner model parameters to be controlled, so $\boldsymbol{x}(t i)=M i(\boldsymbol{k}, \boldsymbol{x}(t 0))$, where $M i(\boldsymbol{k}, \boldsymbol{x}(t 0))$ is represented by $M \circ M \circ \ldots \circ M\left(\mathrm{k}, \mathrm{x}\left(t_{0}\right)\right)$. The tangent linear model is denoted $\mathbf{M}(t i, t i+1)$, which is the Jacobian matrix of $\mathbf{M}$, in $\boldsymbol{x}(t i)$. The adjoint model $\mathbf{M}_{i}^{T}$ is the linear tangent transpose, defined as

$\mathbf{M}_{i}^{T}=\prod_{j=0}^{i-1} \mathbf{M}\left(t_{j}, t_{j+1}\right)^{T}$.

$\mathbf{M}$ is used to estimate variables, which are observed through an observation operator $\mathbf{H}$, permitting one to compare the observed values $\boldsymbol{y}^{0}$ with respect to the $\mathbf{y}$ calculated by the composition $\mathbf{H} \circ \mathbf{M}$, at the location (in time and space) where observations are available. We suppose that $y_{i}=$ $H_{i}\left(M_{i}\left(x_{i}, k\right)\right)+\varepsilon$, where $\varepsilon i$ is a random variable with zero mean. This term represents the sum of the model, observation and scaling error. Finally, the most general form of the cost function is defined as follows:

$$
\begin{aligned}
J(k)= & \frac{1}{2}\left(\boldsymbol{k}-\boldsymbol{k}^{\mathrm{b}}\right)^{T} \mathbf{B}^{-1}\left(\boldsymbol{k}-\boldsymbol{k}^{\mathrm{b}}\right) \\
& +\frac{1}{2} \sum_{i=0}^{t}\left(\boldsymbol{y}_{i}-\boldsymbol{y}_{i}^{0}\right)^{T} \mathbf{R}_{i}^{-1}\left(\boldsymbol{y}_{i}-\boldsymbol{y}_{i}^{0}\right) .
\end{aligned}
$$

The background vector is defined as $\boldsymbol{k}^{\mathrm{b}}$, which is an a priori vector of the inner model parameters. The first part of the cost function represents the discrepancy to $\boldsymbol{k}^{\mathrm{b}}$ and acts as a regularization term. The second part represents the distance between the observations and the model estimates. $\mathbf{B}$ is the covariance error matrix of $\boldsymbol{k}^{\mathrm{b}}$ and $\mathbf{R}_{i}$ is the covariance error matrix of $\boldsymbol{y}^{o}$ at time $t_{i}$.

The objective of this work is to show the capacity of 4DVAR to help determine the value of the principal inner parameters $\boldsymbol{k}$ of SECHIBA and the initial conditions for surface water content. The present distributed software allows the reader to do his or her own experiments using synthetic or actual data. When the observations are synthetic (produced by the model itself), no transfer functions from the estimation to the observation are needed, and $\mathbf{H}$ is taken as the identity matrix. If actual data are used, a specific $\mathbf{H}$ is used that transforms the soil temperature into brightness temperature (see section Model and Data). In addition, the relationship prior value/actual value determines the covariance matrix $\mathbf{B}$; however, in our case no covariance matrix is taken since the actual control parameters values are out of the scope of this work. Finally, in our work, reading the covariance of observations, the identity matrix is taken for $\mathbf{R}$.

The minimization of the cost function (Eq. 4) is based on gradient-descent approaches. The cost function gradient has the form

$\nabla_{k} J=\mathrm{B}^{-1}\left(\boldsymbol{k}-\boldsymbol{k}^{\mathrm{b}}\right)+\sum_{i=1}^{t} \mathbf{M}_{i}^{T}(\boldsymbol{k}) \nabla_{y i} f$,

where $\nabla_{k} J$ and $\nabla_{y i} J$ are the gradients of the cost function $J$ with respect to $\boldsymbol{k}$ and $\boldsymbol{y}_{i}$, respectively.

The expression above allows us to compute $\nabla_{k} J$ by knowing $\nabla_{y i} J$, in the form of a matrix product of this term by the matrix $\mathbf{M}_{i}^{T}(\boldsymbol{x}, \boldsymbol{k})$, corresponding to the transpose of the Jacobian matrix. The development of calculation gives the expression of the gradient of $\boldsymbol{y}$ (Eq. 2):

$\nabla_{k} J=\mathbf{B}^{-1}\left(\boldsymbol{k}-\boldsymbol{k}^{\mathrm{b}}\right)+\sum_{i=1}^{t} \mathbf{M}_{i}^{T}(\boldsymbol{k}) H^{T}\left[R_{i}^{-1}\left(y_{i}-y_{0}\right)\right]$.

The control parameters are adjusted several times using a L-BFGS method (Gilbert and LeMaréchal, 1989) until a stopping criterion is reached.

\subsection{YAO}

Variational data assimilation requires the computation of the adjoint code of the direct model, which is a heavy and complex task, especially for a large model such as SECHIBA. Usually, the adjoint code is computed with the help of specific softwares (automatic differentiators) (e.g., Bischof et al., 1997; Giering and Kaminski, 2003; Hascoët and Pascual, 2004). These softwares are appropriate for the differentiation of large codes, but their use will be optimal only under specific coding conventions and a good level of modularity of the codes (Talagrand, 1991). Moreover, manual optimization of the produced code is often necessary. Therefore, in 


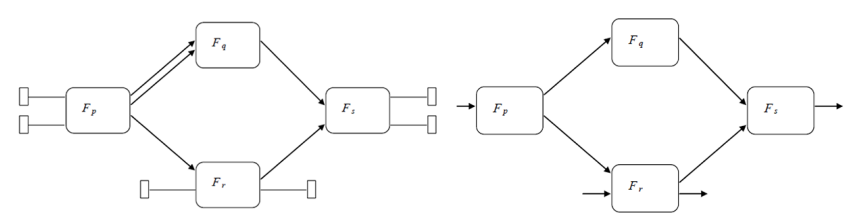

Figure 1. (Left) Example of a modular graph associated with four basic functions and five basic connections, three input points and three output points; (right) simplified description showing the acyclicity of the graph. Source: Nardi et al. (2009).

many practical cases the automatic production of code will not be totally optimal in terms of flexibility (e.g., when the direct model is updated frequently, one has to re-differentiate the whole code). These considerations motivated the development of a slightly different but complementary approach that focuses on the high-level structure of the numerical models, embedding implementation details inside simple entities that can be easily updated. This has led to the development of the YAO assimilation software at LOCEAN/IPSL (https://skyros.locean-ipsl.upmc.fr/ yao/).

YAO is based on the decomposition of a numerical model into elementary modules interconnected by directional links. On the one hand, the structure of the model (variables, dependencies...) is described as a graph structure. On the other hand, the details of the physics are coded inside $\mathrm{C} / \mathrm{C}++$ basic modules that are ideally simple. The user can therefore separate the "high-level" structure of the model from implementation details. It is also very easy to update a numerical code within this framework. Regarding the assimilation strategy, YAO computes the tangent linear and adjoint codes from the elementary Jacobians of each module (provided by the user). Adjoint/cost function test tools are also available. Finally, YAO includes routines devoted to the classical assimilation scenario (incremental form) and is interfaced with the M1QN3 minimizer (Gilbert and LeMaréchal, 1989), which has been designed to minimize functions depending on a very large number of variables not subject to constraints. The algorithm implements a quasi-Newton technique (L-BFGS) with a dynamically updated scalar or diagonal preconditioner. It uses a line search to enforce global convergence; more precisely, the step size is determined by the Fletcher-Lemaréchal algorithm and realizes the Wolfe conditions.

\subsection{Graph formalism}

In YAO, a numerical model must be described as an ensemble of modules related by connections in order to form a graph. Let us define more precisely the main components of the graph.

- A module is a basic entity of computation, representing a deterministic (but possibly nonlinear) function transforming an input vector into an output vector. A module

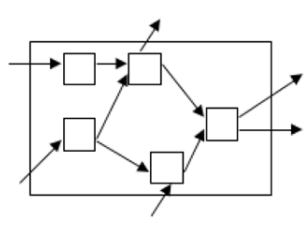

(a)

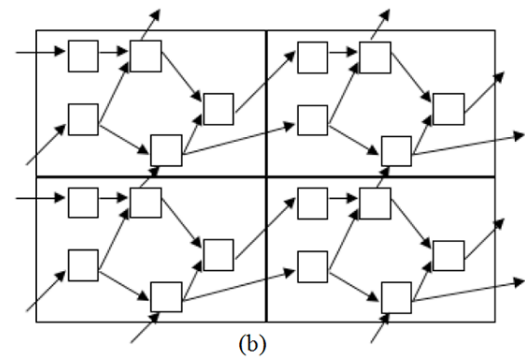

Figure 2. (a) Example of a modular graph with five modules, assumed representative of the pointwise equations of a given model; (b) partial view of the replication of the graph in space. Each elementary graph with five modules is associated with one grid point. Source: Nardi et al. (2009).

is viewed graphically as a node of the graph; the sizes of the vectors correspond to the number of input and output connections associated with the node.

- A basic connection is an oriented link relating two nodes of the graph. Most basic connections usually represent the transmission of the output of one module taken as input by another one.

The external context is the ensemble of data input and output points used as external data by a whole graph at a specific level of abstraction. Basic connections can link a data input point located in the external context to one or several module(s) (for instance, modules needing the specification of some initial conditions, boundary conditions or model parameters). Inversely, the global outputs of the model link a module to a data output point located in the external context.

The modular graph is the ensemble of the modules and of their connections. It must be acyclic so that a topological order may be defined on the nodes of the graph (i.e., if there is connection $F_{p} \rightarrow F_{q}$, then $F_{p}$ should be computed before $F_{q}$ ) (see Fig. 1).

Typically, a modular graph describes the equations governing the system of interest and each physical variable appearing in the governing equations is associated with a specific module. However, supplementary modules can also be defined to represent temporary variables required to simplify computations for complex equations. The user has generally to specify modules at a single point $(i, j, k, t)$ of space $(i, j, k)$ and time $(t)$ and the dependency on space-time locations (e.g., $i+1, j-1, k, t-1$ ) of the discretized variables taken as inputs. From the local description of the equations, YAO is able to build a model on a given space domain and on a given number of time steps by automatically replicating the local graph in space-time (cf. Fig. 2).

By passing the different modules in topological order, YAO is able to emulate the global model and to calculate the global model outputs given model initial conditions and parameters. 
Now, we will see that the usefulness of the graph modular approach is reinforced when the Jacobian matrix of each basic function is known. For a basic function $\mathbf{F}$ such that $y=\mathbf{F}(x)$, the Jacobian matrix $\mathbf{F}$ relates a perturbation of the inputs to the associated perturbation of outputs: $\mathrm{d} y=\mathbf{F} \mathrm{d} x$. Since the Jacobian of a composition of functions is the product of the elementary Jacobians, the tangent linear model associated with a modular graph may also be obtained by passing the graph in the same topological order.

The "lin-forward" algorithm is the following.

1. Initialize the external context data input points with a perturbation $\mathrm{d} x_{i}$ (around a given linearization point).

2. Pass the modules in topological order and propagate the perturbation.

3. Estimate the perturbation output $\mathrm{d} y$ on output data points in the external context of the graph.

Following this procedure, YAO can emulate the global tangent-linear model from elementary Jacobians. In the same manner, a backward algorithm may be defined for adjoint computations. From Eq. (1), it may be shown that the global adjoint will be retrieved by back-propagating the graph, with a few adjustments not detailed here (see Nardi et al., 2009, for more details on the "backward" algorithm). This property is the basis of the semi-automatic adjoint computation by YAO.

An implementation of a variational assimilation procedure with YAO follows the structure represented in Fig. 3. The YAO compiler builds an executable file following the scheme presented in Fig. 3. This file is independent of the assimilation instructions. The executable file reads these instructions from an instruction file. Due to the graph structure of the model and its adjoint, it is easy to modify the model and its adjoint, e.g., by updating some adequate modules; one can systematically obtain the updated global direct model and the global adjoint.

As mentioned in the Introduction, this paper gives access to a compiled version of SECHIBA-YAO and allows one to perform some assimilation experiments related to the control of the 10 most influent internal parameters of SECHIBA by observing the land surface temperature. YAO is a free software that gives the opportunity to modify the SECHIBA code provided in this paper.

\subsection{Development of SECHIBA-YAO}

The implementation of SECHIBA in YAO starts with the definition of the modular graph describing the dynamics of the model (see Appendix A). Elementary processes and interconnections between modules are defined in order to represent the computation flow in the model. The modular graph was built as follows.

- Every component of the original code was carefully studied line by line directly.

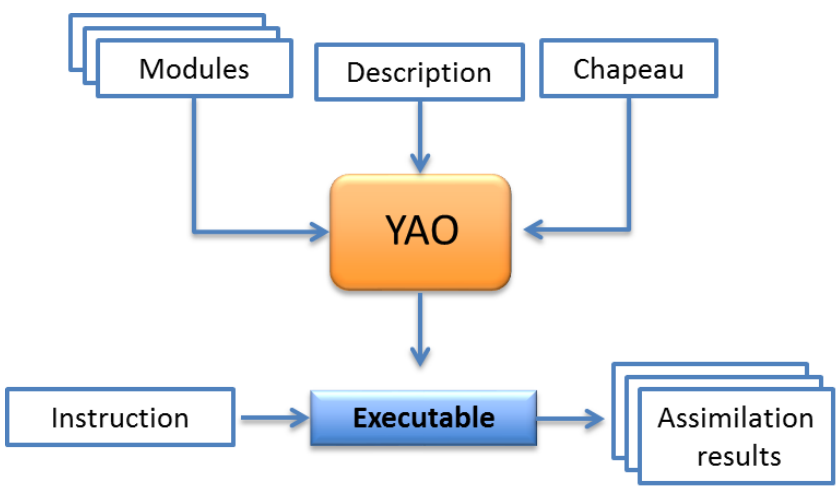

Figure 3. Structure of a project in YAO. The software generates an executable program from input modules, hat and description files. The generated program reads an instruction file to perform assimilation experiments.

- A list of inputs and outputs for each subroutine was made for every routine of SECHIBA. This permits one to know exactly the information flow in the model.

- A second zoom in the subroutines was made in order to understand the internal dynamics of the code. This is the last step in the modular graph definition. When studying the subroutines, their complexity was reduced by breaking the different steps into simpler elements. The idea is to have a scalable code. Uncoupled modules give more independence when changing part of the model. Cohesive modules help to understand the model.

- The original six subroutines in the SECHIBA-Fortran code are split into 130 modules by the SECHIBA-YAO modular graph, corresponding to every process modeled by SECHIBA and to a number of transitional modules serving as auxiliary computing.

- It is important to mention that every variable and subroutine name was kept as in the original model. If a user or developer of SECHIBA-Fortran sees the implementation in YAO, he will find his way easily.

\subsubsection{Direct model}

After defining the modular graph in YAO, the second step in the SECHIBA-YAO implementation is the coding of the direct model and the derivatives of the modules. Every module is represented as a source file and the different processes attributed to the module are implemented inside the source file, allowing a better control of the physics; i.e., any change in the physics could be made easily.

\subsubsection{Module derivatives}

Once the direct model has been coded and validated, there are two options to code the derivatives: they can be coded 
line-by-line based on the forward computing, in order to obtain the Jacobian matrix of the module, or they can also be produced routinely, using an automatic differentiation tool (for example, Tapenade; Hascoet and Pascual, 2013). For SECHIBA-YAO, the derivative process was made line-byline. The outputs are derived with respect to every input. YAO generates automatically, based on these derivatives, the tangent linear and adjoint model.

Nevertheless, the derivative process introduced errors related to the coding process, to inexact derivatives (e.g., expressions that were not differentiable). In order to reduce it to a minimum number of bugs, the adjoint of the model was validated (as it was made with the direct model). This guarantees the accuracy when performing assimilation. The validation of the adjoint model is presented in Sect. 4.1.

\section{Data assimilation experiments}

In this section we present several experiments that have been realized using the SECHIBA-YAO system. They were designed to control the 11 most influential internal parameters of SECHIBA when we assimilate the land surface temperature (LST).

In order to deal with non-dimensional control parameters with the same order of magnitude, preprocessing has been applied. The control parameters were first divided into two groups. The first group includes physical parameters, which have a physical dimension. In the present work, these parameters were normalized by dividing them by their prior values in order to control non-dimensional parameters. In such a way, given that the prior value is the true value (in the case of twin experiments), a value of 1 for these parameters indicates that the control parameter has been correctly reconstructed. The second group corresponds to physical parameters that are multiplied by a "multiplicative factor", which is dimensionless (Verbeeck et al., 2001). The multiplying factors are the control variables of the second group and are set to 1 at the beginning of the assimilation process. The normalization process on the one hand and the use of multiplicative factors on the other hand allow us to deal with numbers of the same order of magnitude, which facilitates the comparison of the sensitivity of the different control variables in the assimilation process.

In the following, all variables are supposed to be preprocessed, so they are normalized and centered around 1.

The model inner parameters are the following (see Table 1): rsol $_{\text {cste }}$ is a numerical constant involved in the soil resistance to evaporation. This parameter limits the soil evaporation, so the greater its value, the lower the evaporation; hum ${ }_{\text {cste }}, \mathrm{mx}_{\text {eau }}$ and $\mathrm{min}_{\text {drain }}$ are related to soil water processes: the higher their values, the more water will be available in the model reservoir, affecting water transfers and especially evapotranspiration; $\mathrm{dpu}_{\mathrm{cste}}$ represents the soil depth in meters. The other parameters are multiplicative factors; they all have a value equal to $1: k_{\mathrm{rveg}}$, which is used in the calculation of the stomatal resistance, limits the transpiration capacity of leaves; the greater its value, the lower the transpiration; $k_{\text {emis }}$ controls the soil emissivity used to compute land surface temperature. This parameter takes part in the net radiation calculation which determines the energy balance between incoming and outgoing surface fluxes; $k_{\text {albedo }}$ weights the surface albedo, which is defined as the reflection coefficient for shortwave radiation; $k_{\text {cond }}$ and $k_{\text {capa }}$ take part in the thermal soil capacity and conductivity, both involved in the computation of the soil thermodynamics, and $\mathrm{kz} 0$ weights the roughness height, which determines the surface turbulent fluxes. Since the control parameters are normalized, we apply a perturbation which is of the form of a random noise limited up to $50 \%$ of the true parameter whose value is 1 , so the perturbed value belongs to $[0.5,1.5]$. If the control parameter values posterior to the assimilation process are close to 1 , it means that the assimilation was successfully achieved. Differences between the values retrieved and the prior values represent relative errors in the parameter estimation posterior to assimilation.

In order to show the benefit of data assimilation in SECHIBA, we conducted several experiments using SECHIBA-YAO. Prior to the assimilation process, different scenarios were defined for the tests (Table 3). A scenario makes reference to the experimental conditions. It includes the definition of the vegetation functioning type (PFT), the type of observation to be assimilated, the observation sampling, the time sampling, the atmospheric forcing file, the subset of control parameters, the assimilation window size and the time of the year to start the assimilation. The different scenarios were calculated using the adjoint model for several typical conditions of the two FLUXNET sites selected. The dates presented in this paper are representative of sunny days in summer or winter, with no perturbation coming from clouds and without rainfall events. In Eq. (4), we take $\mathbf{R}$ as the identity matrix, which means that we assume the errors of the observations are uncorrelated. The next section explains the scenarios for the different experiments performed in this work.

\subsection{Variational sensitivity analysis}

In order to show the accuracy of the distributed SECHIBAYAO code, we present an analysis that allows us to rank the 11 parameters according to their sensibility estimated by using the adjoint model and to compare the results to those obtained by using finite differences. We identify the most sensitive parameters to the estimation of land surface temperature (LST) by computing the gradients obtained with the adjoint model. This analysis corresponds to a first-order sensitivity estimate of the influence of the control parameters on the land surface temperature. In order to do so, local sensitivities were determined by computing the parameter gradients both by finite difference and by adjoint calculation (Saltelli, 
Table 1. SECHIBA inner parameters used in this work. There are five inner parameters involved in the model estimations that are controlled, plus six multiplicative factors, all equal to 1 .

\begin{tabular}{llll}
\hline Parameter & Description & Prior value & Unit \\
\hline rsol $_{\text {cste }}$ & Evaporation resistance & 33000 & $\mathrm{~S} \mathrm{~m}^{-2}$ \\
hum $_{\text {cste }}$ & Water stress & $\{5,2\}$ & $\mathrm{m}^{-1}$ \\
mx $_{\text {eau }}$ & Maximum water content & 150 & $\mathrm{Kg} \mathrm{m}^{-3}$ \\
min $_{\text {drain }}$ & Diffusion between reservoirs & 0.001 & $\mathrm{~S} \mathrm{~m}^{-2}$ \\
$\mathrm{dpu}_{\text {cste }}$ & Total depth of soil water pool & 2 & $\mathrm{~m}$ \\
\hline
\end{tabular}

Table 2. Sensitivity analysis results. Parameter hierarchy according to each site and vegetation fraction. The parameters are ranked by decreasing sensibility.

\begin{tabular}{|c|c|c|}
\hline Site & Bare soil (PFT 1) & Agricultural C3 crop (PFT 12) \\
\hline Harvard Forest & $\begin{array}{l}k_{\text {emis }}, k_{\text {cond }}, k_{\text {capa }}, k_{z 0}, k_{\text {albedo }}, \mathrm{dpu}_{\mathrm{cste}} \\
\text { rsol }_{\text {cste }}, \mathrm{mx}_{\text {eau }}, \min _{\text {drain }}, k_{\text {rveg }}, \text { hum }_{\text {cste }}\end{array}$ & $\begin{array}{l}k_{\text {emis }}, k_{\text {rveg }}, k_{\text {cond }}, k_{\text {capa }}, k_{z 0}, \mathrm{mx}_{\text {eau }}, \\
\text { hum }_{\text {cste }}, k_{\text {albedo }}, \mathrm{dpu}_{\mathrm{cste}}, \mathrm{rsol}_{\mathrm{cste}}, \\
\min _{\text {drain }}\end{array}$ \\
\hline Kruger Park & $\begin{array}{l}k_{\mathrm{emis}}, k_{\mathrm{cond}}, k_{\mathrm{capa}}, k_{z 0}, k_{\mathrm{albedo}}, \mathrm{dpu}_{\mathrm{cste}}, \\
\text { rsol }_{\mathrm{cste}}, \mathrm{mx}_{\mathrm{eau}}, \min _{\mathrm{drain}}, k_{\mathrm{rveg}}, \text { hum }_{\mathrm{cste}}\end{array}$ & $\begin{array}{l}k_{\text {emis }}, k_{\text {rveg }}, k_{\text {cond }}, k_{\text {capa }}, k_{z 0}, \mathrm{mx}_{\text {eau }}, \\
\text { hum }_{\text {cste }}, k_{\text {albedo }}, \text { dpu }_{\text {cste }}, \text { rsol }_{\text {cste }}, \\
\min _{\text {drain }}\end{array}$ \\
\hline
\end{tabular}

2008). This method is really local and the information provided is related to a definite point in space. The values of the inner parameters (Table 1) and multiplicative factors (all equal to 1) represent the initial values where the experiments have been conducted. Because hum cste $_{\text {is related to vegeta- }}$ tion type, in this work only the values for PFT $1\left(5 \mathrm{~m}^{-1}\right)$ and PFT $12\left(2 \mathrm{~m}^{-1}\right)$ are considered.

The sensitivity analysis was performed for a subset of inner parameters related to the energy and water physical processes on bare soil (PFT 1) and agricultural C3 crop (PFT 12), in order to quantify the role of the vegetation in the land surface temperature parameters' sensitivity. The land functional types are useful for distinguishing the different soil types. In the present case we used the agricultural C3 grass type whose parameters are $V_{c \max }$, opt (optimal maximum RuBisCO-limited potential photosynthetic capacity) $=90 \mathrm{~mol} / \mathrm{m}^{-2} \mathrm{~s}^{-1} ; T_{\text {opt }}$ (optimum photosynthetic temperature) $=27.5+0.25 \mathrm{Tl}^{\circ} \mathrm{C}$; $\mathrm{Tl}$ (function of multiannual mean temperature for $\mathrm{C} 3$ grasses); max $x_{\mathrm{LAI}}$ (maximum leaf area index (LAI) beyond which there is no allocation of biomass to leaves) $=6$; $z_{\text {root }}$ (exponential depth scale for root length profile $)=0.25 \mathrm{~m}$; leaf (prescribed leaf albedo $)=$ 0.18 ; $h$ (prescribed height of vegetation) $=0.4 \mathrm{~m}$; Ac (critical leaf senescence) $=150$ days; $T_{\mathrm{S}}$ (weekly temperature beyond which leaves are shed if the seasonal temperature trend is negative) $=10^{\circ} \mathrm{C}$; and $H_{\mathrm{S}}$ (weekly moisture stress beyond which leaves are shed) $=0.2$.

The work was done on a daily basis, in order to observe the diurnal variations of sensitivities. At each half-hour time step, model outputs are computed. At each time step, a gradient is computed in order to have the updated gradient value. As we make the assumption that the errors in prior values are very large in comparison with errors in observations, we discard the background term in the cost function (defined in Sect. 2). This simplification is valid as soon as the system is overdetermined (i.e., the number of control parameters is smaller than the number of observations). The initial values of the parameters (before optimization) are those of Table 1. We recall that for numerical purposes, the control parameters have been normalized in order to have the same order of magnitude (i.e., equal to 1). Calculations were performed for both FLUXNET sites considered in this work.

Figure 4 compares, for 28 August 1996 at Harvard Forest, the sensitivities computed for each control parameter with both finite differences and model gradients. Bare soil results are presented in Fig. 4a. The agricultural C 3 crop scenario is illustrated in Fig. 4b. The efficiency of the adjoint calculation is first demonstrated in these plots, because the 11 desired parameter sensitivities are obtained in a single integration, whereas it takes 11 runs of the model to compute the same quantity using finite differences. By using the same methodology, sensitivity curves were computed at FLUXNET site Kruger Park (Fig. 5). The comparison between sensitivity analysis done using the adjoint and using finite differences shows a very good agreement between the two methods for both sites. The diurnal characteristics of the parameter sensitivities with a maximum around noon in phase with the diurnal variation of solar radiation are clearly visible.

Table 2 presents, for Harvard Forest and Kruger Park, the 11 parameters ranked with respect to their influence. According to the four scenarios defined (two sites and two PFTs), it can be seen that the hierarchy changes with the vegetation but remains the same for both sites. Parameter hierarchy revealed that the highest gradient values correspond to those 
Table 3. Scenario properties and description.

\begin{tabular}{ll}
\hline Properties & Description \\
\hline $\begin{array}{l}\text { Assimilation period } \\
\text { Number of assimilations }\end{array}$ & $\begin{array}{l}\text { Time window of the assimilation period } \\
\text { For each experiment, a number of assimilations are made with the same scenario but with dif- } \\
\text { ferent control parameter initial values. } \\
\text { Parameters to be optimized in the assimilation procedure. The number of parameters depend } \\
\text { on the experiment. They are chosen among the following parameters: } k_{\mathrm{emis}}, k_{\mathrm{cond}}, k_{\mathrm{capa}}, k_{z 0}, \\
k_{\mathrm{albedo}}, \mathrm{dpu}_{\mathrm{cste}}, \mathrm{rsol}_{\mathrm{cste}}, \mathrm{mx}_{\mathrm{eau}} \text { min }_{\mathrm{drain}}, k_{\mathrm{rveg}}, \mathrm{hum}_{\mathrm{cste}}\end{array}$ \\
$\begin{array}{l}\text { Model variables considered as observations: } L S T \text { in the present study } \\
\text { Observations }\end{array}$ & $\begin{array}{l}\text { Frequency sampling of the observations } \\
\text { Observation sampling }\end{array}$ \\
$\begin{array}{l}\text { Forcing } \\
\text { Vegetation type }\end{array}$ & Vegetation fraction considered in the experiment
\end{tabular}

that have the largest influence on the land surface temperature estimate. Clearly $k_{\mathrm{emis}}$ is the most influential parameter in the calculation of land surface temperature, regardless of the climatology used and vegetation fraction. In addition, $\min _{\text {drain }}$ is the least influential parameter for all scenarios.

The parameters $k_{\text {capa }}, k_{\text {cond }}, k_{\text {zo }}$ and $k_{\text {albedo }}$ are the most influential in bare soil conditions, after $k_{\text {emis }}$. In the presence of vegetation, several sensitivities change radically: $k_{\text {rveg }}$ becomes the most important multiplicative factor after $k_{\text {emis }}$; the factor $k_{\text {albedo }}$ is less sensitive compared to its influence in the bare soil case and $\mathrm{mx}_{\mathrm{eau}}$ is more sensitive, given that less water is available when a fraction of vegetation is present. The other parameters show equivalent sensitivity values regardless of the scenario. For hum cste $_{\text {and }} k_{\text {rveg }}$, sensitivities are equal to 0 for bare soil, because these parameters affect surface temperature only in the presence of vegetation.

Parameters with persistent positive sensitivity are rsol $_{\mathrm{cste}}$,

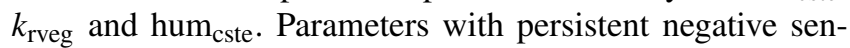
sitivity are $k_{\mathrm{z} 0}, k_{\text {albedo }}$ and emis. The sign of the gradients reflects the positive or negative feedback on the surface temperature of the processes involved. For example, the parameters involved in the evapotranspiration processes present negative sensitivities because a reduction of (or an increase in) the evapotranspiration will lead to an increase (or a decrease) in the land surface temperature when the soil water content is sufficient.

Transpiration processes influence directly the land surface temperature in the presence of vegetation and are the dominant processes at the studied sites. Therefore $k_{\text {rveg }}$ has a higher sensitivity than $k_{\text {cond }}, k_{\text {capa }}$ and $k_{\text {albedo. }}$. For bare soil, by contrast, the dominant processes are those related to the soil thermodynamics, explaining why $k_{\text {capa }}, k_{\text {cond }}$ and $k_{\text {emis }}$ are the most sensitive parameters.

In general, sensitivities are higher in bare soil conditions for the control parameters, except for $\min _{\text {drain }}$ and $\mathrm{mx}_{\mathrm{eau}}$. Since $\min _{\text {drain }}$ is not sensitive to the land surface temperature, this parameter is no longer controlled. Only the 10 most influential parameters are used in the following sections.
The next section presents the different assimilation experiments that we have performed using the SECHIBA-YAO software.

\subsection{Twin experiments}

Twin experiments permit one to check the robustness of the variational assimilation method by assimilating synthetic data. First the direct model is run with a set of parameters Ptrue (the initial conditions) in order to produce pseudo observations of land surface temperature LST. Then Ptrue is randomly noised to obtain Pnoise. Assimilations of land surface temperature LST were then performed in the model run with Pnoise as new initial conditions for the control parameters during several days (most of the time, 1 week), leading to a new set of optimized parameters denoted as Passim. Passim is then compared to Ptrue in order to estimate the performances of the assimilation process. Five different assimilation experiments were performed. These experiments are available in the distributed version of SECHIBA-YAO.

\subsubsection{Definition of experiments}

The 10 most sensitive parameters are considered in the twin experiments (all the above parameters except $\min _{\text {drain }}$ ). We present hereinafter the results obtained with different assimilation realizations. Each assimilation experiment was conducted by perturbing the initial conditions of the control parameters with a uniform distribution random noise reaching $50 \%$ of the parameter nominal values. This procedure permitted us to obtain the relative errors of the control parameters and the root mean square error (RMSE) of the model fluxes, based on their value before and after the assimilation process.

A scenario for a single experiment is defined by several properties described in Table 3. Scenarios for all the assimilation experiments are presented in Table 4. All parameters are controlled at the same time. The duration of each assimilation experiment is 1 week or 1 month, depending on the experiment. The time steps $\Delta T$ of each experiment are $30 \mathrm{~min}$, ex- 

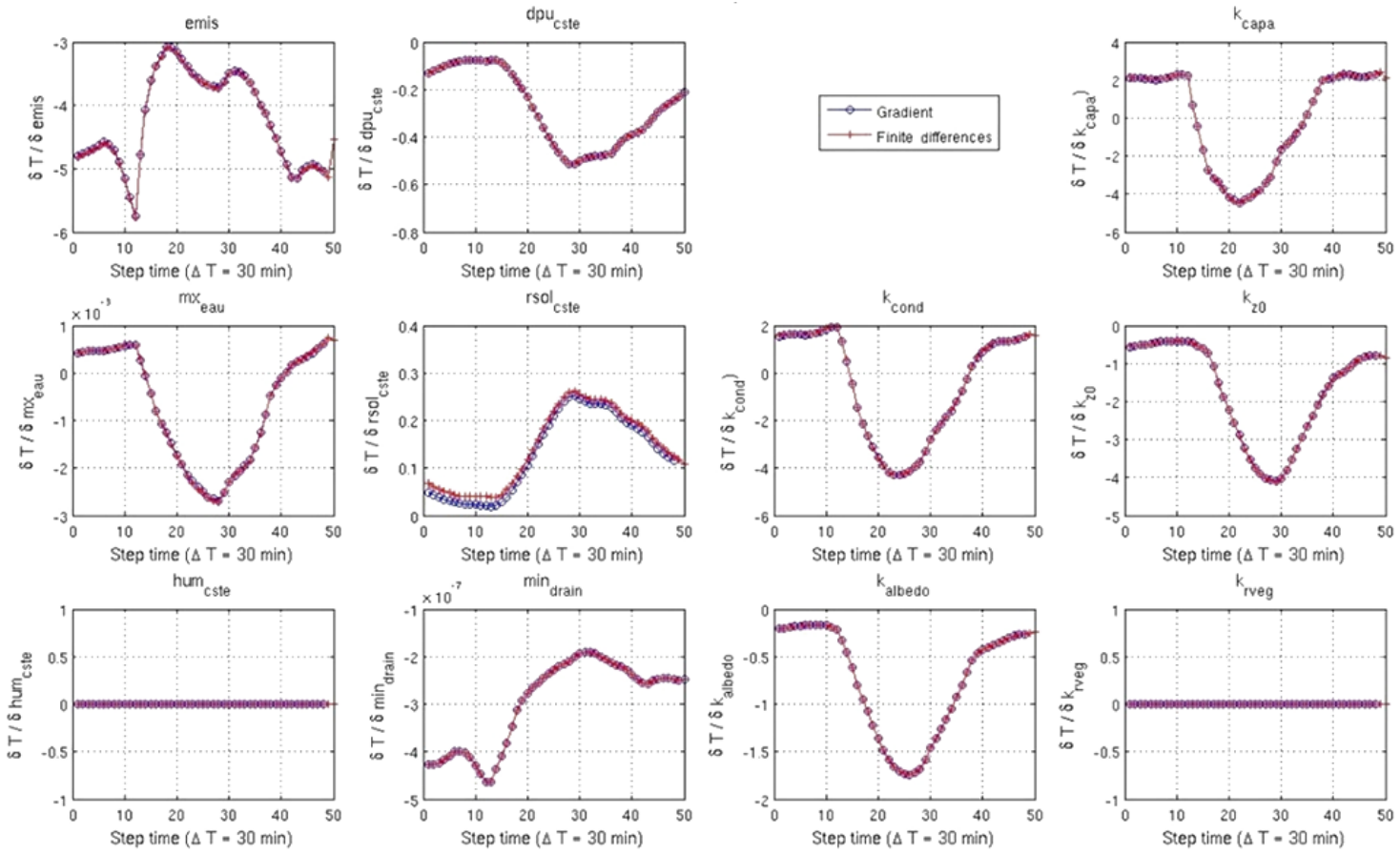

(a)
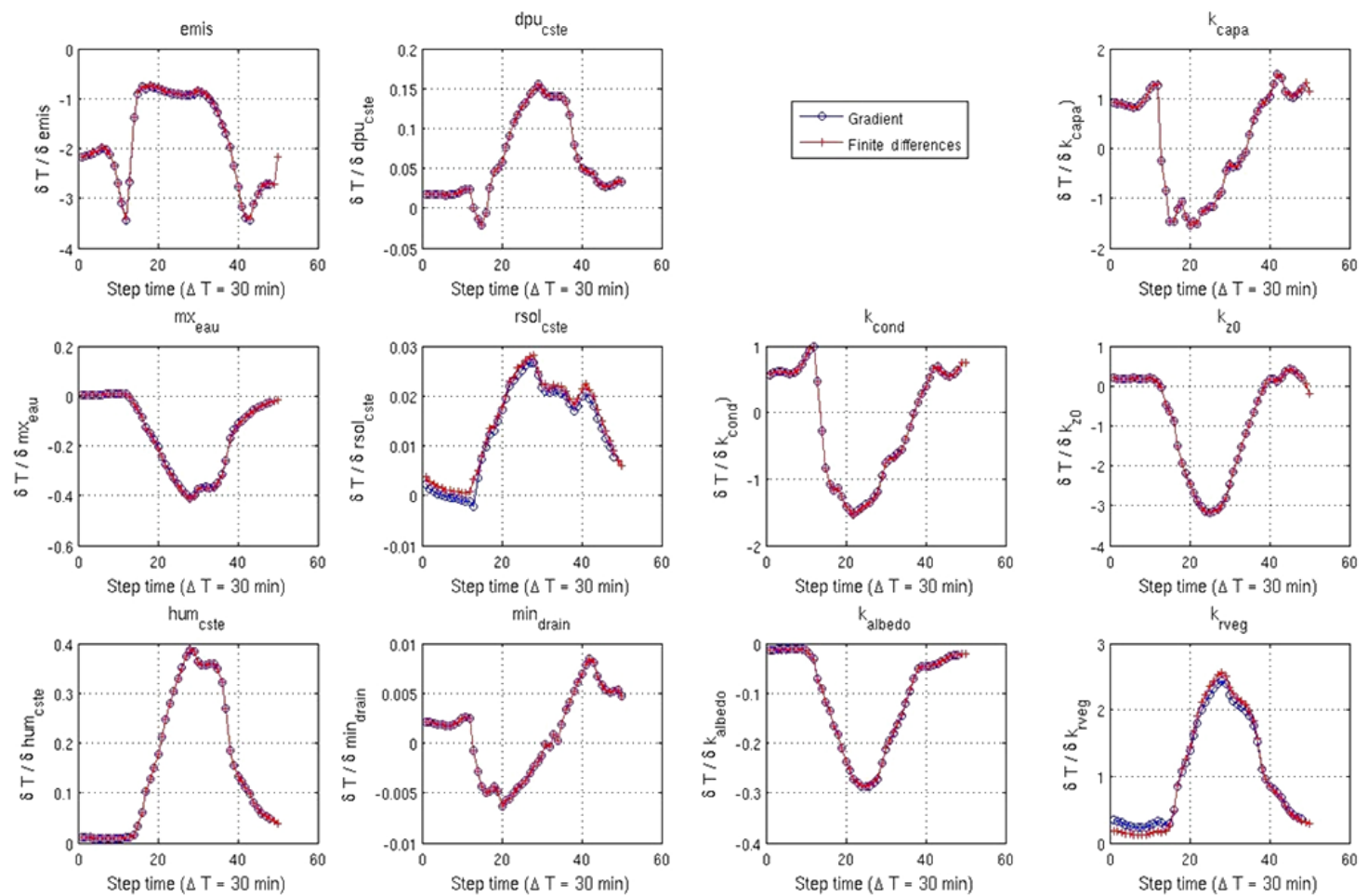

(b)

Figure 4. Comparisons for 28 August 1996 at Harvard Forest of the sensitivities obtained for each control parameter with both the finite differences and the model gradients computed with the adjoint model. Sensitivity analysis results for PFT 1 are in (a) and for PFT 12 in (b). The sensitivities were computed on the surface temperature for Harvard Forest. Blue curves represent the LST derivative with respect to each parameter given by the adjoint each half hour over a day. Red curves represent the LST derivative computed with a finite difference discretization of the model. 

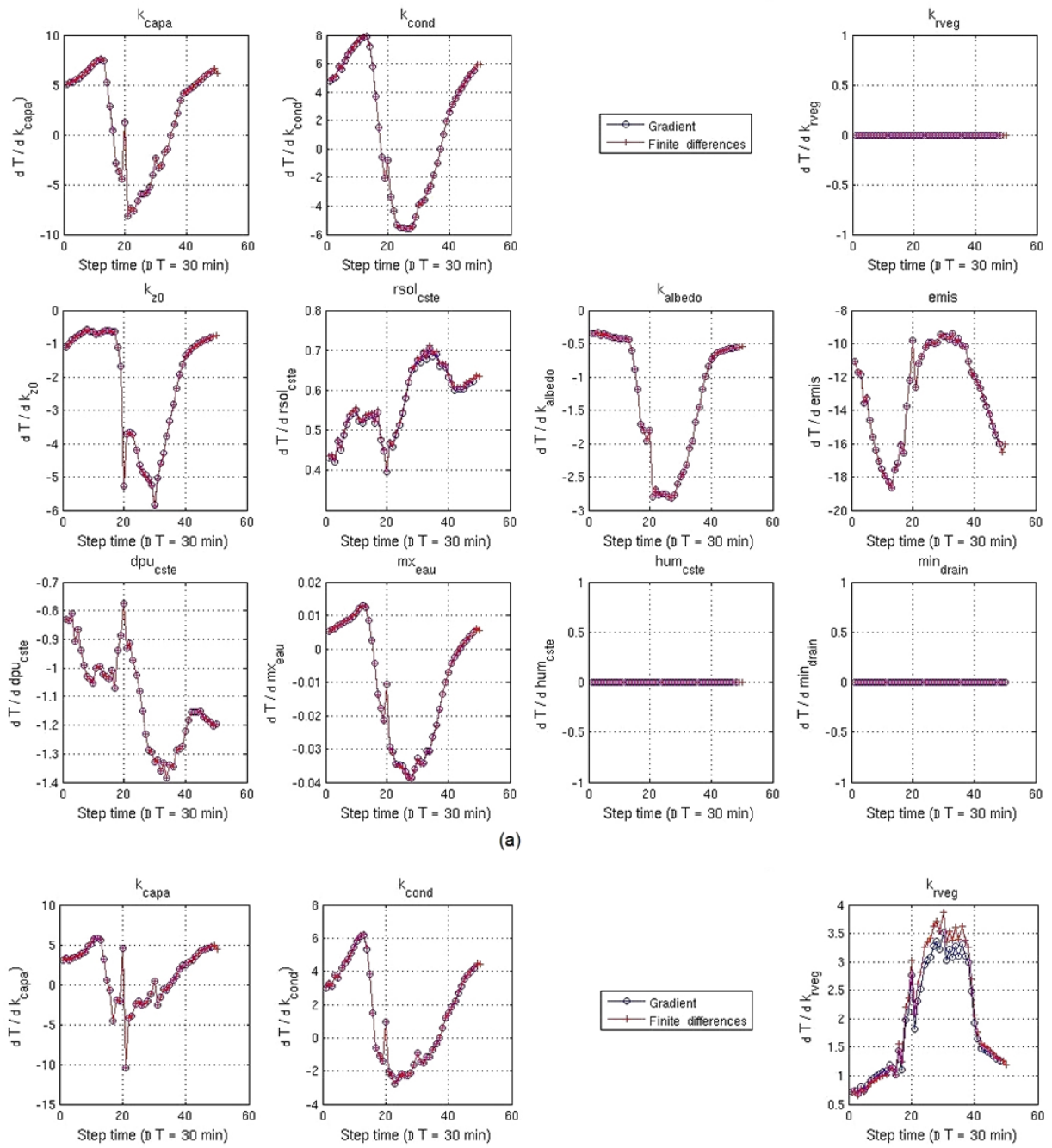

a)
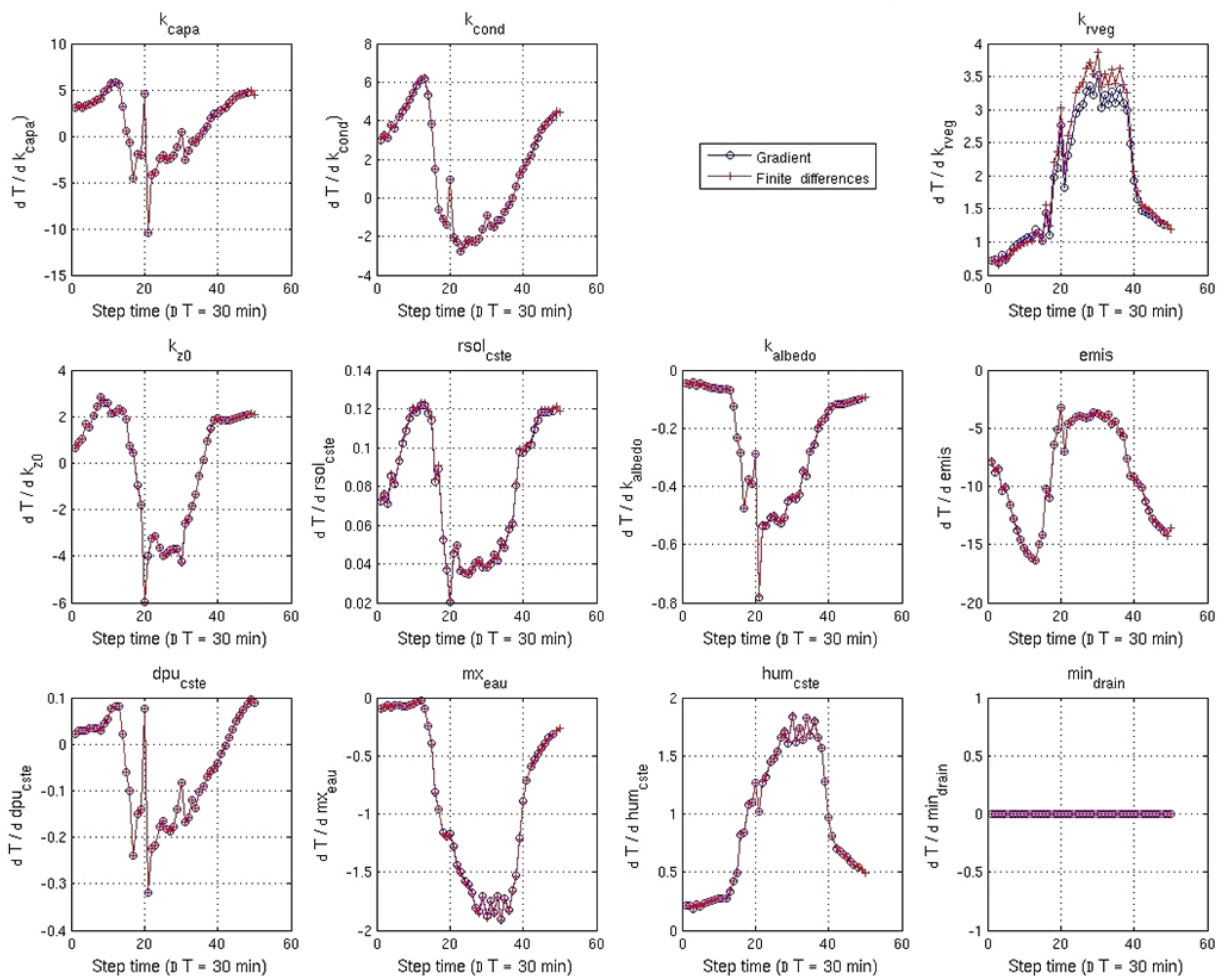

(b)

Figure 5. Comparisons for 11 February 2003 at the Kruger Park site of the sensitivities obtained for each control parameter with both the finite differences and the model gradients computed with the adjoint model. Sensitivity analysis results for PFT 1 are in (a) and for PFT 12 in (b). The sensitivities were computed on the surface temperature. Blue curves represent the LST derivative with respect to each parameter given by the adjoint each half hour over a day. Red curves represent the LST derivative computed with a finite difference discretization of the model. 
Table 4. Characteristics of the scenarios for each of the twin experiments.

\begin{tabular}{|c|c|c|c|c|c|}
\hline Scenario & Experiment 1 & Experiment 2 & Experiment 3 & Experiment 4 & Experiment 5 \\
\hline $\begin{array}{l}\text { Assimilation } \\
\text { period }\end{array}$ & $\begin{array}{l}\text { 11/02/2003, } 1 \text { month } \\
\text { Kruger Park } \\
\text { 28/08/1996, } 1 \text { month } \\
\text { Harvard Forest }\end{array}$ & $\begin{array}{l}\text { 11/02/2003, } 1 \text { week } \\
\text { (Kruger Park) } \\
\text { 28/08/1996, 1 week } \\
\text { (Harvard Forest) }\end{array}$ & $\begin{array}{l}\text { 11/02/2003, } 1 \text { week } \\
\text { (Kruger Park) } \\
\text { 28/08/1996, } 1 \text { week } \\
\text { (Harvard Forest) }\end{array}$ & $\begin{array}{l}\text { 11/02/2003, } 1 \text { week } \\
\text { (Kruger Park) } \\
\text { 28/08/1996, 1 week } \\
\text { (Harvard Forest) }\end{array}$ & $\begin{array}{l}\text { 11/02/2003, } 1 \text { week } \\
\text { (Kruger Park) } \\
\text { 28/08/1996, } 1 \text { week } \\
\text { (Harvard Forest) }\end{array}$ \\
\hline $\begin{array}{l}\text { Number of as- } \\
\text { similations }\end{array}$ & $\begin{array}{l}5 \text { experiments } \\
\text { for each site }\end{array}$ & $\begin{array}{l}500 \text { experiments for } \\
\text { each site }\end{array}$ & $\begin{array}{l}5 \text { experiments for } \\
\text { each site }\end{array}$ & $\begin{array}{l}5 \text { experiments for } \\
\text { each site }\end{array}$ & $\begin{array}{l}5 \text { experiments for } \\
\text { each site }\end{array}$ \\
\hline $\begin{array}{l}\text { Control param- } \\
\text { eters }\end{array}$ & $\begin{array}{l}k_{\text {rveg }}, k_{\text {emis }}, k_{\text {cond }} \\
k_{\text {capa }}, k_{z 0}, k_{\text {albedo }}\end{array}$ & $\begin{array}{l}k_{\text {rveg }}, k_{\text {emis }}, k_{\text {cond }} \\
k_{\text {capa }}, k_{z 0}, k_{\text {albedo }}\end{array}$ & $\begin{array}{l}k_{\text {emis }}, k_{\text {cond }}, k_{\text {capa }} \\
k_{z 0}, k_{\text {albedo }}\end{array}$ & $\begin{array}{l}k_{\text {emis }}, k_{\text {rveg }}, k_{\text {cond }} \\
k_{\text {capa }}, k_{z 0}\end{array}$ & $\begin{array}{l}\text { All parameters, ex- } \\
\text { cept } \min _{\text {drain }}\end{array}$ \\
\hline Observations & Soil temperature & $\begin{array}{l}\text { Soil temperature } \\
\text { with noise }\end{array}$ & Soil temperature & Soil temperature & Soil temperature \\
\hline $\begin{array}{l}\text { Observation } \\
\text { sampling }\end{array}$ & $\begin{array}{l}30 \mathrm{~min}, 2,6,12 \text { and } \\
24 \mathrm{~h}\end{array}$ & $1 \mathrm{~h}$ & $30 \mathrm{~min}$ & $30 \mathrm{~min}$ & $30 \mathrm{~min}$ \\
\hline Forcing & $\begin{array}{l}\text { Kruger Park and Har- } \\
\text { vard Forest }\end{array}$ & $\begin{array}{l}\text { Kruger Park and } \\
\text { Harvard Forest }\end{array}$ & $\begin{array}{l}\text { Kruger Park and Har- } \\
\text { vard Forest }\end{array}$ & $\begin{array}{l}\text { Kruger Park and } \\
\text { Harvard Forest }\end{array}$ & $\begin{array}{l}\text { Kruger Park and } \\
\text { Harvard Forest }\end{array}$ \\
\hline Vegetation type & PFT 12 & PFT 12 & PFT 1 & PFT 12 & PFT 12 \\
\hline
\end{tabular}

Table 5. Sampling frequencies for Experiment 1.

\begin{tabular}{rlrr}
\hline $\begin{array}{r}\text { Test } \\
\text { number }\end{array}$ & $\begin{array}{l}\text { Sampling } \\
\text { frequencies }\end{array}$ & $\begin{array}{r}\text { Observations } \\
\text { per day }\end{array}$ & $\begin{array}{r}\text { Observation } \\
\text { per month }\end{array}$ \\
\hline 1 & $30 \mathrm{~min}$ & 48 & 1440 \\
2 & $2 \mathrm{~h}$ & 24 & 720 \\
3 & $6 \mathrm{~h}$ & 4 & 120 \\
4 & $12 \mathrm{~h}$ & 2 & 60 \\
5 & $24 \mathrm{~h}$ & 1 & 30 \\
\hline
\end{tabular}

cept for Experiment 1, where the time step varies. All experiments presented in this work use Harvard Forest and Kruger Park as forcing. For each experimental setting, five different assimilation realizations were made, except for Experiment 2 , where 500 independent assimilations were run. The mean errors are presented in Table 4.

- In Experiments 1 and 2, the six most sensitive parameters are controlled. In both cases the vegetation type is PFT 12. In Experiment 1 several observation assimilation samplings are tested, going from $30 \mathrm{~min}$ up to $24 \mathrm{~h}$. During 1 month, five independent assimilation tests were run for each observation sampling. In Experiment 2 , a weighted random noise was introduced in the observations, going from 10 up to $50 \%$ of the true value of the observation. Both Experiments 1 and 2 use constant perturbations of the control parameters $(50 \%$ of its prior value for Experiment 1 and $10 \%$ for Experiment 2 ) in order to assess the impact of varying the observation sampling and the noise in the observations.

- In Experiment 3 the five most sensitive parameters according to the sensitivity analysis (Table 2) were controlled in bare soil conditions (PFT 1) at the Harvard
Forest and Kruger Park sites. In this experiment the noise added on the prior values is $50 \%$.

- In Experiment 4 the five most sensitive parameters for each PFT were controlled in the conditions of agricultural C3 (PFT 12), according to the sensitivity analysis (Table 2), in the Harvard Forest and Kruger Park sites. In doing so, we were able to assess the effect of the vegetation fraction on the assimilation system. In addition, taking only the most sensitive parameters in the control set permitted us to increase the assimilation performances, given that the more the observed variable is sensitive to a parameter, the easier the minimization process finds its optimal value, consequently reducing the estimation error. In this experiment the noise added on the prior values is $50 \%$.

- In Experiment 5, all parameters, except $\min _{\text {drain }}$, were controlled (since min $_{\text {drain }}$ has no impact on the land surface temperature estimation), during a week in Harvard Forest and Kruger Park.

Comparing Experiment 5 with Experiments 3 and 4 allows us to study the impact of taking a larger number of control parameters on the assimilation process. In addition, we want to test whether LST observation provides enough information to constrain all the model parameters at the same time and whether we can hope to improve all model state variables. In this experiment the noise added on the prior values is $50 \%$.

\subsection{Results}

\subsubsection{Effect of the observation sampling}

Experiment 1 investigates the impact of the observation sampling ( $30 \mathrm{~min}, 2 \mathrm{~h}, 6 \mathrm{~h}, 12 \mathrm{~h}, 24 \mathrm{~h}$ ) in the assimilation, since 
Table 6. Results of Experiment 1 using the Harvard Forest and Kruger Park sites. (a) The first two columns give the computed fluxes prior to the assimilation. The last five columns present the RMSE (prior-estimated) for each run. (b) The first two columns give the noise interval (in \%) introduced for each control parameter with respect to the initial value of 1 . The last five columns present the relative error in $\%$ in the control parameters for the five sampling frequencies reported in Table 5.

\begin{tabular}{|c|c|c|c|c|c|c|c|}
\hline \multicolumn{3}{|c|}{ (a) } & \multicolumn{5}{|c|}{ RMSE } \\
\hline & Fluxes & Prior & 1 & 2 & 3 & 4 & 5 \\
\hline \multirow[t]{3}{*}{ Kruger Park } & $H\left(\mathrm{~W} \mathrm{~m}^{-2}\right)$ & 25 & 0.437 & 0.138 & 0.43 & 4.7 & 10.34 \\
\hline & $\mathrm{LE}\left(\mathrm{W} \mathrm{m}^{-2}\right)$ & 15.7 & 0.0601 & 0.592 & 0.594 & 2.43 & 10.8 \\
\hline & $\operatorname{LST}(\mathrm{K})$ & 7.98 & 0.0601 & 0.0243 & 0.592 & 0.594 & 1.9 \\
\hline \multirow[t]{3}{*}{ Harvard Forest } & $H\left(\mathrm{~W} \mathrm{~m}^{-2}\right)$ & 13.42 & 0.15 & 0.98 & 1.84 & 3.98 & 4.08 \\
\hline & $\mathrm{LE}\left(\mathrm{W} \mathrm{m}^{-2}\right)$ & 86.23 & 0.22 & 0.35 & 3.81 & 5.17 & 11.95 \\
\hline & $\operatorname{LST}(\mathrm{K})$ & 5.98 & 0.08 & 0.65 & 0.86 & 1.27 & 1.61 \\
\hline \multirow[t]{2}{*}{ (b) } & & & \multicolumn{5}{|c|}{ Error (in \%) } \\
\hline & Control parameters & Noise interval in $\%$ & 1 & 2 & 3 & 4 & 5 \\
\hline \multirow[t]{6}{*}{ Kruger Park } & $k_{\text {cond }}$ & 50 & 0.0183 & 0.261 & 0.340 & 0.921 & 4.96 \\
\hline & $k_{\text {capa }}$ & 50 & 0.0427 & 0.172 & 0.4006 & 0.91 & 3.77 \\
\hline & $k_{\mathrm{z} 0}$ & 50 & 0.00103 & 0.0162 & 0.147 & 0.24 & 1.34 \\
\hline & $k_{\text {rveg }}$ & 50 & 0.418 & 0.909 & 3.845 & 4.01 & 14.97 \\
\hline & $k_{\mathrm{emis}}$ & 50 & 0.1704 & 0.2733 & 0.77 & 1.27 & 4.4 \\
\hline & $k_{\text {albedo }}$ & 50 & 0.128 & 1.384 & 3.214 & 4.15 & 25.01 \\
\hline \multirow[t]{6}{*}{ Harvard Forest } & $k_{\text {cond }}$ & 50 & 0.37 & 0.54 & 3.7 & 5.7 & 10.14 \\
\hline & $k_{\text {capa }}$ & 50 & 0.36 & 2.86 & 4.16 & 10.55 & 20.74 \\
\hline & $k_{\mathrm{z} 0}$ & 50 & 0.0592 & 0.15 & 7.61 & 13.74 & 16.73 \\
\hline & $k_{\text {rveg }}$ & 50 & 0.31 & 0.75 & 5.25 & 7.24 & 17.8 \\
\hline & $k_{\text {emis }}$ & 50 & 0.11 & 0.17 & 5.82 & 10.86 & 13.74 \\
\hline & $k_{\text {albedo }}$ & 50 & 1.54 & 4.81 & 12.69 & 34.11 & 37.8 \\
\hline
\end{tabular}

varying the observation frequency leads to varying the number of observations available. Each test was labeled with a number. This number serves as a reference to compare the different results. Table 5 presents the several tests we conducted as well as their initial conditions. For example, in Test 4 , only two observations per day are taken at noon and at midnight. In Test 5, we have one observation per day, taken at noon, and so on.

Prior and final errors before and posterior to the assimilation process are presented in Table 6 for the Kruger Park and Harvard Forest sites. The columns represent the different assimilations performed with different frequency sampling in the observations. Five independent assimilations were done for each test. Table 6 reports the mean value of the performances of the assimilation system. Even though small errors were found for the different tests, we do notice that the assimilation system is sensitive to the observation sampling.

The contribution of the observations is demonstrated by an improvement in the optimization when increasing the frequency of observations, both for the controlled parameters and the computed fluxes $H$ and LE that are major outputs of the model. The final error values in the different tests increase by a factor of 10 when reducing the sampling frequency.

\subsubsection{Effect of random noise in the observation}

Experiment 2 aims at studying the impact of introducing a random noise in the synthetic observations. The random noise follows a normal distribution with zero mean and variance 1 . The perturbed observations are computed using the following equation:

$\left.\mathrm{LST}^{*}=\mathrm{LST}+\right] \mathrm{amp} \cdot \varphi$,

with LST* the perturbed observation, LST the original land surface temperature, amp a factor weighting the random noise going from 10 to $50 \%$, and $\varphi$ the normal distribution random noise. The control parameter set is composed of the six most influential parameters in the computation of LST. The initial conditions of the parameters are obtained by perturbing them $10 \%$ uniformly from their prior values. Three tests were performed, aiming to check the impact of introducing different magnitudes of errors prior to the assimilation process. Results are presented in Table 7. The mean value of the 500 independent assimilations is presented. Posterior to each experiment, the parameter relative error and the model flux RMSE are computed to quantify the quality of the results. 
Table 7. Experiment 2 (different amplitudes of random noise in the observations) using the Harvard Forest and Kruger Park sites. We present the mean values for 500 experiments: (a) the first two columns give the computed fluxes prior to the assimilation. The last three columns present the RMSE (prior minus estimated) for a given level of noise added to the observations (10, 30, 50\%). (b) The first two columns give the noise interval (in \%) introduced for each control parameter with respect to the initial value of 1 . The last three columns present the mean error in $\%$ in the control parameters for different levels of noise $(10,30,50 \%)$ added to the observations (LST).

\begin{tabular}{llrrrr}
\hline (a) & & \multicolumn{4}{c}{ RMSE } \\
\hline \multirow{2}{*}{ Kruger Park } & Fluxes & Prior & $10 \%$ & $30 \%$ & $50 \%$ \\
& $H\left(\mathrm{~W} \mathrm{~m}^{-2}\right)$ & 24.7 & 7.26 & 7.81 & 8.32 \\
& LE $\left(\mathrm{W} \mathrm{m}^{-2}\right)$ & 4.06 & 3.78 & 3.9 & 6.22 \\
& LST $(\mathrm{K})$ & 7.12 & 0.019 & 4.48 & 6.23 \\
\hline \multirow{2}{*}{ Harvard Forest } & $H\left(\mathrm{~W} \mathrm{~m}^{-2}\right)$ & 25 & 5.92 & 11.13 & 24.01 \\
& LE $\left(\mathrm{W} \mathrm{m}^{-2}\right)$ & 15.7 & 4.77 & 14.04 & 15.05 \\
& LST $(\mathrm{K})$ & 7.98 & 0.046 & 1.42 & 2.59 \\
\hline \multirow{2}{*}{ (b) } & & & Mean error & $(\%)$ \\
\hline \multirow{2}{*}{ Kruger Park } & Control parameters & Noise interval in $\%$ & $10 \%$ & $30 \%$ & $50 \%$ \\
& $k_{\text {cond }}$ & 10 & 4.5 & 4.9 & 11.12 \\
& $k_{\text {capa }}$ & 10 & 1.51 & 3.35 & 14.9 \\
& $k_{z 0}$ & 10 & 3.24 & 3.99 & 4.09 \\
& $k_{\text {rveg }}$ & 10 & 6.91 & 10.1 & 11.5 \\
& $k_{\text {emis }}$ & 10 & 2.79 & 3.14 & 4.08 \\
& $k_{\text {albedo }}$ & 10 & 1.12 & 2.01 & 3.02 \\
\hline Harvard Forest & $k_{\text {cond }}$ & 10 & 0.83 & 4.32 & 7.6 \\
& $k_{\text {capa }}$ & 10 & 4.47 & 9.05 & 9.21 \\
& $k_{z 0}$ & 10 & 3.85 & 4.5 & 7.3 \\
& $k_{\text {rveg }}$ & 10 & 1.36 & 7.01 & 8.04 \\
& $k_{\text {emis }}$ & 10 & 2.39 & 3.62 & 6.47 \\
& $k_{\text {albedo }}$ & 10 & 1.02 & 2.58 & 7.85 \\
\hline
\end{tabular}

We note in Table $7 \mathrm{a}$ and $\mathrm{b}$ that the parameter restitution is degraded when adding random noise to the observations. This shows that the sensitivity of the assimilation system to the noise affecting the LST observations is quite high. When increasing the amplitude of the error, the various errors obtained for the three tests not only suggest the need to take into account the quality of the observations in the model, but also the fact that the parameters are not affected in the same way by the data uncertainties. However, perturbations are still limited and a deeper exploration should be performed to assess the impact on the assimilation performance of noisy observations.

\subsubsection{Effect of the control parameter set size}

The RMSE errors of the assimilations for Experiments 3, 4 and 5 are presented in Tables 8 and 9, corresponding to the Harvard Forest and Kruger Park sites. For all the experiments the noise added on the parameters was $50 \%$. In Experiment 3 for PFT 1, the mean errors in the retrieved values for all the control parameters are on the order of $10^{-8}$. Regarding the LST retrieval, the mean RMSE ranges from $4.82 \mathrm{~K}$ prior to assimilation to $2.1 \times 10^{-5} \mathrm{~K}$ after the assimilation process.
The same behavior is observed for the different model fluxes. Both FLUXNET sites used as forcing have more or less the same behavior with regards to the error reduction. In Experiment 4 for PFT 12, similar results were observed. The assimilation process permits the reduction of the parameter errors for both sites and both PFTs used (Table 8b). In Experiment 5 , the relative value of the RMSE with respect to the synthetic measurements, for LST, LE and $H$, is reduced at both FLUXNET sites. The same results hold for the mean relative error of the control parameters.

Comparing the results from Experiments 3 and 4 to Experiment 5, degradation in fluxes and parameter restitution can be observed. Effectively, we find higher errors in the fluxes and the final control parameters when increasing the size of the control parameter set (Experiment 5). The best performances in the parameter restitution are obtained when controlling five parameters only. When we control the 10 most sensitive parameters, as in Experiment 5, degradation in the final value of the parameters is observed. Indeed, the larger the control parameter set, the more easily the cost function may converge toward a local minimum (that can be far from the global optimum). In addition, it is difficult to retrieve accurately parameters that are insensitive to LST; thus, the as- 
Table 8. Results for Experiments 3 (PFT 1) and 4 (PFT 12). RMSE of model fluxes (a) and parameter relative errors (b) before and after the assimilation process on FLUXNET Harvard Forest and Kruger Park.

\begin{tabular}{|c|c|c|c|c|c|}
\hline \multirow[t]{3}{*}{ (a) } & \multirow{3}{*}{ Fluxes } & \multicolumn{4}{|c|}{ RMSE } \\
\hline & & \multicolumn{2}{|c|}{ Experiment 3 (PFT 1) } & \multicolumn{2}{|c|}{ Experiment 4 (PFT 12} \\
\hline & & Prior & Final & Prior & Final \\
\hline \multirow[t]{3}{*}{ Kruger Park } & $H\left(\mathrm{~W} \mathrm{~m}^{-2}\right)$ & 4.22 & $4.1 \times 10^{-12}$ & 2.18 & $2.4 \times 10^{-9}$ \\
\hline & $\operatorname{LE}\left(\mathrm{W} \mathrm{m}^{-2}\right)$ & 4.51 & $2.6 \times 10^{-4}$ & 6.86 & $3.2 \times 10^{-5}$ \\
\hline & $\operatorname{LST}(\mathrm{K})$ & 7.15 & $2.3 \times 10^{-5}$ & 2.32 & $8.3 \times 10^{-9}$ \\
\hline \multirow[t]{3}{*}{ Harvard Forest } & $H\left(\mathrm{~W} \mathrm{~m}^{-2}\right)$ & 2.33 & $2.2 \times 10^{-12}$ & 1.52 & $1.5 \times 10^{-10}$ \\
\hline & $\mathrm{LE}\left(\mathrm{W} \mathrm{m}^{-2}\right)$ & 2.45 & $7.3 \times 10^{-4}$ & 8.34 & $2.4 \times 10^{-6}$ \\
\hline & $\operatorname{LST}(\mathrm{K})$ & 5.14 & $4.3 \times 10^{-5}$ & 1.37 & $7.1 \times 10^{-10}$ \\
\hline \multirow[t]{3}{*}{ (b) } & & \multicolumn{4}{|c|}{ Mean error $(\%)$} \\
\hline & Control parameters & \multicolumn{2}{|c|}{ Experiment 3 (PFT 1) } & \multicolumn{2}{|c|}{ Experiment 4 (PFT 12} \\
\hline & & Prior & Final & Prior & Final \\
\hline \multirow[t]{6}{*}{ Kruger Park } & $k_{\text {cond }}$ & 25.4 & $3.17 \times 10^{-11}$ & 27.3 & $6.37 \times 10^{-6}$ \\
\hline & $k_{\text {capa }}$ & 25.3 & $3.1 \times 10^{-11}$ & 27.3 & $5.64 \times 10^{-6}$ \\
\hline & $k_{\mathrm{z} 0}$ & 25.1 & $6.7 \times 10^{-11}$ & 26.3 & $7.97 \times 10^{-5}$ \\
\hline & $k_{\text {rveg }}$ & - & - & 28.1 & $2.76 \times 10^{-6}$ \\
\hline & $k_{\text {emis }}$ & 25.8 & $3.01 \times 10^{-11}$ & 27.5 & $6.08 \times 10^{-5}$ \\
\hline & $k_{\text {albedo }}$ & 25.9 & $5.2 \times 10^{-11}$ & - & - \\
\hline \multirow[t]{6}{*}{ Harvard Forest } & $k_{\text {cond }}$ & 24.1 & $5.58 \times 10^{-5}$ & 26.9 & $5.85 \times 10^{-6}$ \\
\hline & $k_{\text {capa }}$ & 25.4 & $5.57 \times 10^{-6}$ & 25.8 & $7.84 \times 10^{-7}$ \\
\hline & $k_{\mathrm{z} 0}$ & 24.4 & $1.27 \times 10^{-5}$ & 25.8 & $7.84 \times 10^{-7}$ \\
\hline & $k_{\text {rveg }}$ & - & - & 22.1 & $8.31 \times 10^{-6}$ \\
\hline & $k_{\text {emis }}$ & 25.5 & $5.71 \times 10^{-4}$ & 24.2 & $5.96 \times 10^{-7}$ \\
\hline & $k_{\text {albedo }}$ & 23.4 & $1.99 \times 10^{-4}$ & - & - \\
\hline
\end{tabular}

similation of this variable in order to optimize these parameters is not efficient.

\section{Discussion and conclusion}

In this study the adjoint of SECHIBA was implemented using adjoint semi-generator software denoted YAO. The land surface temperature gradients with respect to each control parameter were computed by SECHIBA-YAO, which permitted us to carry out a sensitivity analysis of the parameter influence on the synthetic LST estimation on the one hand and to conduct several assimilation experiments on the other hand.

The first contribution of this paper was the sensitivity analysis results. They showed exactly which parameters of the model are the most sensitive and have to be controlled during the assimilation process. However, it is important to mention that sensitivity analysis depends on the region, the forcing, the PFT, and the time period (hour and day), among other factors. Once the parameter hierarchy was set, twin experiments were performed for different scenarios, aiming at testing the robustness of the assimilation scheme.
The second contribution of this work is that we showed the usefulness of the variational data assimilation of LST (land surface temperature) for improving the SECHIBA parameter estimations. LST assimilation has the potential to improve the LSM parameter calibration, by adjusting them properly during the control process. In a forecasting approach, this can be valuable, due to the fact that the simulation can be more reliable, since the model parameters are fitted on actual measurements. Improvement in the fluxes computed by the model after the assimilation of LST was demonstrated. Twin experiments showed the power of variational data assimilation to improve the model parameter estimation. Different experiments conducted for different scenarios and forcing sites were successfully accomplished, meaning that a reduction in the fluxes errors was obtained by introducing information given by the LST synthetic observations. In addition, the influence of the size of the control parameter set in the assimilation performance was proven.

Estimating only the most sensitive parameters to LST increases our chances of finding acceptable values for them after assimilation. Optimizing a larger control parameter set, as in Experiment 5, makes it more difficult for the assimilation 
Table 9. Results for Experiment 5 (PFT 12). RMSE of model fluxes (a) and parameter relative errors (b) before and after the assimilation process, on the FLUXNET Harvard Forest and Kruger Park sites.

\begin{tabular}{|c|c|c|c|}
\hline \multirow[t]{3}{*}{ (a) } & & \multicolumn{2}{|c|}{ RMS } \\
\hline & \multirow[t]{2}{*}{ Fluxes } & \multicolumn{2}{|c|}{ Experiment 5 (PFT 12) } \\
\hline & & Prior & Final \\
\hline \multirow[t]{3}{*}{ Kruger Park } & $H\left(\mathrm{~W} \mathrm{~m}^{-2}\right)$ & 30.4 & 2.1 \\
\hline & $\mathrm{LE}\left(\mathrm{W} \mathrm{m}^{-2}\right)$ & 34.1 & 3.1 \\
\hline & $\operatorname{LST}(\mathrm{K})$ & 3.12 & $3.2 \times 10^{-1}$ \\
\hline \multirow[t]{3}{*}{ Harvard Forest } & $H\left(\mathrm{~W} \mathrm{~m}^{-2}\right)$ & 41.5 & 5.4 \\
\hline & $\mathrm{LE}\left(\mathrm{W} \mathrm{m}^{-2}\right)$ & 24.1 & 2.3 \\
\hline & $\operatorname{LST}(\mathrm{K})$ & 5.2 & $5.1 \times 10^{-1}$ \\
\hline \multirow[t]{3}{*}{ (b) } & & \multicolumn{2}{|c|}{ Mean error (\%) } \\
\hline & Control parameters & \multicolumn{2}{|c|}{ Experiment 5 (PFT 12) } \\
\hline & & Prior & Final \\
\hline \multirow[t]{10}{*}{ Kruger Park } & $k_{\text {cond }}$ & 23.4 & $2.3 \times 10^{-1}$ \\
\hline & $k_{\text {capa }}$ & 26.6 & $2.1 \times 10^{-1}$ \\
\hline & $k_{\mathrm{Z} 0}$ & 22.2 & $1.5 \times 10^{-1}$ \\
\hline & $k_{\text {rveg }}$ & 25.9 & $3.1 \times 10^{-1}$ \\
\hline & $k_{\mathrm{emis}}$ & 24.5 & $2.3 \times 10^{-1}$ \\
\hline & $k_{\text {albedo }}$ & 23.8 & $1.8 \times 10^{-1}$ \\
\hline & $\mathrm{mx}_{\text {eau }}$ & 26.3 & $6.8 \times 10^{-1}$ \\
\hline & hum $_{\text {cste }}$ & 22.4 & $1.9 \times 10^{-1}$ \\
\hline & dpu $\mathrm{cste}_{\mathrm{c}}$ & 25.6 & $3.2 \times 10^{-1}$ \\
\hline & rsol $_{\text {cste }}$ & 23.1 & $1.9 \times 10^{-1}$ \\
\hline \multirow[t]{10}{*}{ Harvard Forest } & $k_{\text {cond }}$ & 25.1 & $3.30 \times 10^{-1}$ \\
\hline & $k_{\text {capa }}$ & 26.7 & $2.61 \times 10^{-1}$ \\
\hline & $k_{\mathrm{z} 0}$ & 25.4 & $1.79 \times 10^{-1}$ \\
\hline & $k_{\text {rveg }}$ & 27.5 & $2.8 \times 10^{-1}$ \\
\hline & $k_{\mathrm{emis}}$ & 26.3 & $2.1 \times 10^{-1}$ \\
\hline & $k_{\text {albedo }}$ & 24.7 & $2.37 \times 10^{-1}$ \\
\hline & $m x_{\text {eau }}$ & 25.8 & $7.34 \times 10^{-1}$ \\
\hline & hum $_{\text {cste }}$ & 25.2 & $2.7 \times 10^{-1}$ \\
\hline & $\mathrm{dpu}_{\mathrm{cste}}$ & 24.2 & $2.2 \times 10^{-1}$ \\
\hline & rsol $_{\text {cste }}$ & 25.4 & $2.36 \times 10^{-1}$ \\
\hline
\end{tabular}

system to retrieve the prior value of the control parameters with a high accuracy. After presenting the different experiments, some aspects of data assimilation arise when analyzing the results. The first one concerns the presence of several local minima due to the nonlinearity of the SECHIBA model. Second, we have also shown a significant improvement in the assimilation performances when the sampling frequency of observations is increased, as evaluated in Experiment 1. This suggests that the ability of the model to be constrained depends, among other things, on the observation frequency. By decreasing the number of observations, the control parameter adjustment is less accurate, and the assimilation procedure estimates variables with a larger error. Therefore it can be verified that if we have more LST observations, the assimilation system will fit the parameters better so improved estimations are obtained.
Finally, we observe a strong dependence between the quality of observations and the parameter restitution, as shown in Experiment 2. It seems crucial to take into account the uncertainty in the observations, because they do not affect the assimilation performance in the same way when estimating each parameter in the minimization process. If we compare Experiments 1 and 2 (Tables 6 and 7), it is clear that the noise on the observations dramatically increases the mean error on the computed fluxes $L$ and $H$; the LSTs that are assimilated, are retrieved with a better accuracy. The introduction of a regularization term on the parameters could be used to mitigate this problem. Constraining parameters and weighting observations according to their confidence in the minimization phase can be modeled through the introduction in the cost function of the variance-covariance error matrices (background $\mathbf{B}$ and observation $\mathbf{R}$ ). It is an important aspect to consider for assimilating real observations.

Adding extra parameters to the control set increases the complexity of the cost function. By taking into consideration the results of assimilation of LST when controlling the 10 most sensitive parameters (Experiment 5), we could see that, after having made several assimilation runs, LST does not provide enough information to constrain the parameter set, in order to improve the estimation of the SECHIBA parameters. In the case of controlling all parameters we cannot hope to improve the estimation of all model parameters unless we assimilate additional observations or we add a background term in the cost function.

Assimilation with the YAO approach permits the implementation of different assimilation scenarios in a very flexible way when performing different twin experiments: the control parameters and the observed variables (once the adjoint code has been generated), the assimilation windows, the observation sampling, the time sampling and other different features can be changed easily.

A distributed version of SECHIBA-YAO code and several examples with different scenarios are available at a GitHub dedicated site. YAO can be downloaded upon request at https://skyros.locean-ipsl.upmc.fr/ yao/. Direct use of this software will allow one to perform other experiments using different physical conditions or even to change several equations of the model.

\section{Code and data availability}

The distributed version of SECHIBA-YAO provides an opportunity for scientists to perform their own assimilation. The distributed version allows the control of the five most influent internal parameters of SECHIBA, depending on the vegetation type. In addition, LST or satellite brightness temperature can be used as observations.

The distributed version of SECHIBA-YAO is available in a GitHub repository (https://github.com/brajard/sechibavar/ archive/v1.0.zip); the user can download the software, save 
it in a local repertory and run the makefile in order to build a local executable. Documentation and two instruction files are available in order to guide the user towards their own implementation. Users can modify the forcing file, the initial date to the assimilation, the parameter value and their perturbation if needed. The assimilation frame (1 week), the step time $(30 \mathrm{~min})$, the observed variable (land surface temperature), the control parameters (only five) and other initial parameters are imposed. If a user wants to have access to a full modifiable version, the YAO software has to be installed (https://skyros.locean-ipsl.upmc.fr/_yao/).
The instruction files given with the distributed version correspond to the twin experiments presented in this paper. Initial parameters like the assimilation time frame and the observed variable (LST) cannot be changed in the distributed version. However, the other initial parameters used to build different scenarios can be changed easily through the instruction file (initial parameter values, PFT, observation files, forcing, initial date, etc.). 


\section{Appendix A: SECHIBA-YAO}

The version of SECHIBA implemented in YAO includes the two-layer hydrology of Choisnel (1977), mentioned in Sect. 2. SECHIBA original code is implemented in a modular scheme with a set of well-defined routines, independent in its processes and with a single entry point (a main routine handling the rest of the functionalities).

A set of prognostic variables is defined for each module and its assignation depends on the forcing conditions, physical phenomena, etc. SECHIBA can work coupled with the other components of ORCHIDEE (STOMATE and LPJ) or it can be used offline, as it was used in this work. Once SECHIBA is coded in YAO, it can be easily coupled with the other modules of ORCHIDEE.

In SECHIBA, the different routines were originally coded in the Fortran language and can be run at any resolution and over any region of the globe. The version of SECHIBA implemented in YAO is denoted SECHIBA-YAO and follows the Fortran code. In its present form, it can only be run at one point at a time.

ORCHIDEE uses MODIPSL and IOIPSL in its internal processes (see http://forge.ipsl.jussieu.fr/igcmg/wiki/ platform/documentation for more information). Developed at IPSL, the first one is a set of scripts allowing the extraction of a given configuration from a computing machine and the compilation of the specific machine configuration components. MODIPSL is the tree that will host models and tools for configuration. IOIPSL helps to manage the variables state history, variable normalization, and file lecture, among others.

The main routines in SECHIBA-Fortran are presented in Fig. A1. These are also the routines considered in the YAO implementation of the model. First, DIFFUCO computes the diffusion and plant transpiration coefficients based on the atmospheric conditions, solar fluxes, dry soil height, soil moisture stress and fraction of vegetation. ENERBIL corresponds to the energy budget module. Surface energy fluxes related to the soil are computed, based on atmospheric conditions, radiative fluxes, resistances, surface-type fractions and surface drag. HYDROLC is the hydrological budget module, taking as inputs the rainfall, snowfall, evaporation components, soil temperature profile and vegetation distribution. CONDVEG helps in the computation of the vegetation conditions. The thermodynamics of the model is computed in THERMOSOIL, based on a seven-layer soil profile. Finally, SLOWPROC computes the soil slow processes. When SECHIBA is decoupled from STOMATE, this module also deals with the LAI evolution.

The different SECHIBA components are interconnected as shown in Fig. A2. The output of the different modules serves as inputs for the next one, thus resulting in an interdependency among modules to be considered when modeling SECHIBA-YAO.

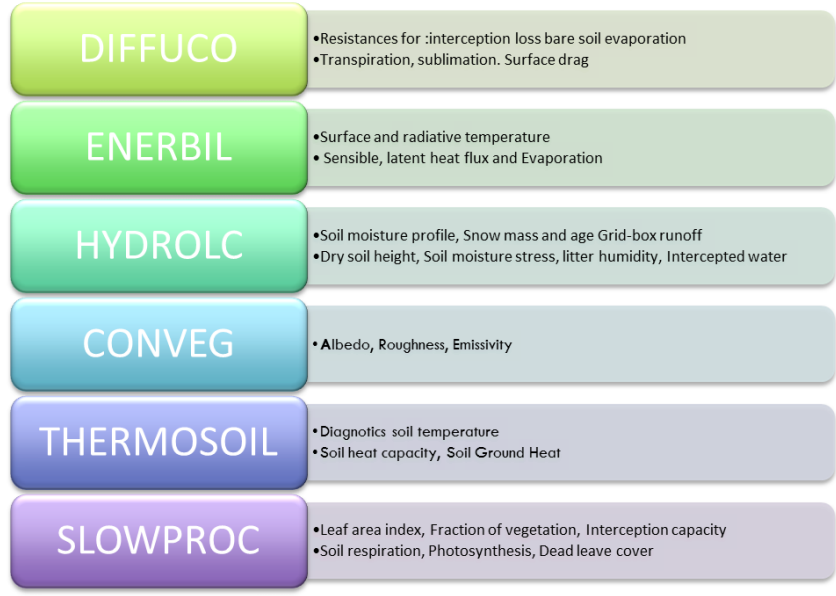

Figure A1. SECHIBA subroutines and their corresponding outputs. Source: Benavides Pinjosovsky (2014).

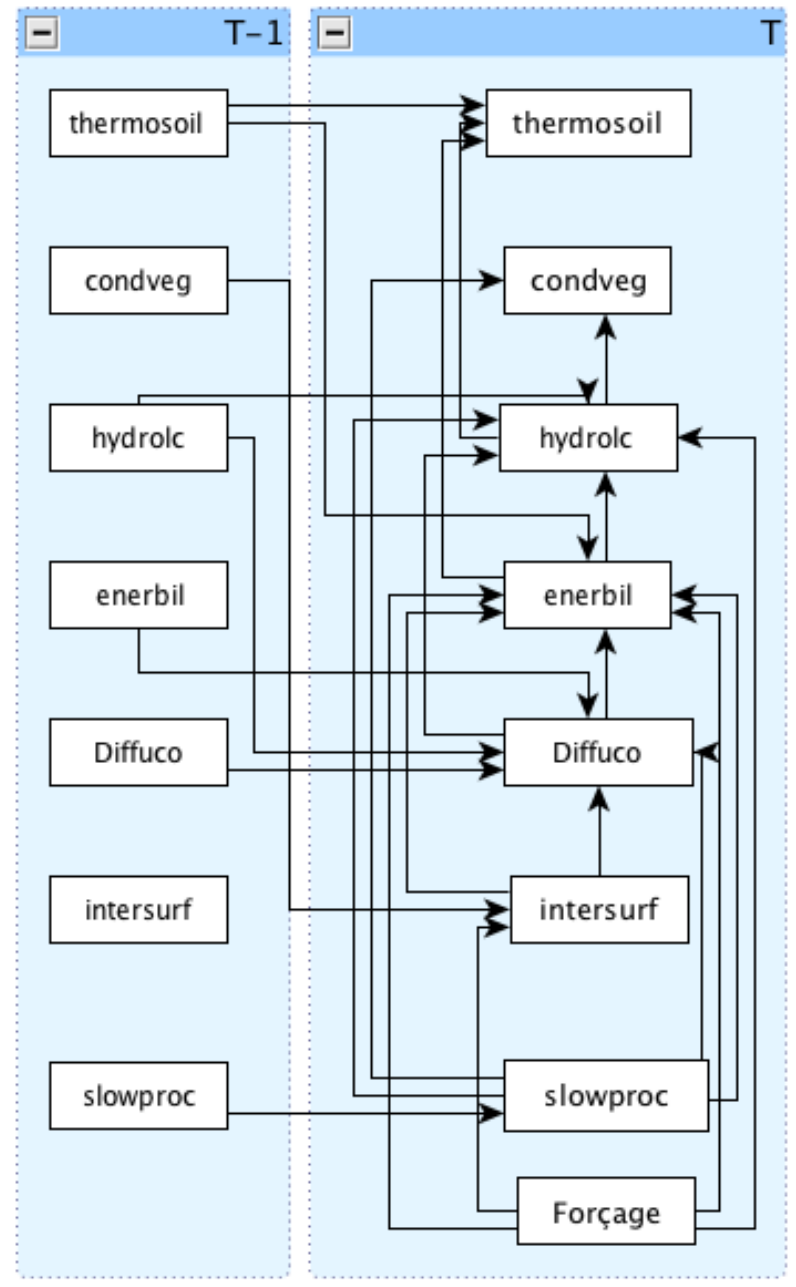

Figure A2. SECHIBA hyper-graph, showing general model dynamics. Source: Benavides Pinjosovsky (2014). 
Acknowledgements. This work used eddy covariance data acquired by the FLUXNET community and in particular by the following networks: AmeriFlux (U.S. Department of Energy, Biological and Environmental Research, Terrestrial Carbon Program and AfriFlux) and the global FLUXNET project (http://daac.ornl.gov/FLUXNET/fluxnet.html). A special thanks to M. Crepon from LOCEAN for his active participation in the revision of this article. P. Peylin and F. Chevalier are acknowledged for fruitful discussions. We thank also F. Maignan for her continuous support in the use of the ORCHIDEE model, and M. Berrondo for the assistance in writing this article.

Edited by: J. Kala

Reviewed by: B. Coudert, R. Mechri, and A. Kallel

\section{References}

Aubinet, M., Vesala, T., and Papale, D.: Eddy Covariance: A Practical Guide to Measurement and Data Analysis, Springer Atmospheric Sciences Editions, United States of America, 2012.

Baldocchi, D., Falge, E., Gu, L., Olson, R., Hollinger, D., Running, S., Anthoni, P., Bernhofer, C., Davis, K., Evans, R., Fuentes, J., Goldstein, A., Katul, G., Law, B., Lee, X., Malhi, Y., Meyers, T., Munger, W., Oechel, W., Paw, K. T., Pilegaard, K., Schmid, H. P., Valentini, R., Verma, S., Vesala, T., Wilson, K., and Wofsy, S.: FLUXNET: a new tool to study the temporal and spatial variability of ecosystemscale carbon dioxide, water vapor, and energy flux densities, B. Am. Meteorol. Soc., 82, 2415-2434, doi:10.1175/15200477(2001)082<2415:FANTTS>2.3.CO;2, 2001.

Bateni, S. M., Entekhabi, D., and Jeng, D. S.: Variational assimilation of land surface temperature and the estimation of surface energy balance components, J. Hydrol., 481, 143-156, doi:10.1016/j.jhydrol.2012.12.039, 2013.

Benavides Pinjosovsky, H. S.: Variarional data assimilation in the land surface model ORCHIDEE using YAO, Earth Sciences, Université Pierre et Marie Curie - Paris VI, available at: http: //www.theses.fr/2014PA066590, last access: 14 September 2014.

Bischof, C. H., Bouaricha, A., Khademi, P. M., and Mor, J. J.: Computing gradients in large-scale optimization using automatic differentiation, Informs J. Comput., 9, 185-194, 1997.

Castelli, F., Entekhabi, D., and Caporali, E.: Estimation of surface heat flux and an index of soil moisture using adjoint-state surface energy balance, Water Resour. Res., 35, 3115-3125, doi:10.1029/1999WR900140, 1999.

Choisnel, E.: Le bilan d'Énergie et le bilan hydrique du sol, Paris, Météorologie Nationale, 1977.

d'Orgeval, T., Polcher, J., and Li, L.: Uncertainties in modelling future hydrological change over west africa, Clim. Dynam., 26, 93-108, doi:10.1007/s00382-005-0079-3, 2006.

Ducoudré, N., Laval, K., and Perrier, A.: SECHIBA, a new set of parametrizations of the hydrologic exchanges at the land/atmosphere interface within the LMD atmospheric general circulation model, J. Climate, 6, 248-273 doi:10.1175/15200442(1993)006<0248:SANSOP>2.0.CO;2, 1993.

Dufresne, J. L., Foujols, M. A., Denvil, S., Caubel, A., Marti, O., Aumont, O., Balkanski, Y., Bekki, S., Bellenger, H., Benshila, R., Bony, S., Bopp, L., Braconnot, P., Brockmann, P., Cadule,
P., Cheruy, F., Codron, F., Cozic, A., Cugnet, D., de Noblet, N., Duvel, J. P., Ethe, C., Fairhead, L., Fichefet, T., Flavoni, S., Friedlingstein, P., Grandpeix, J. Y., Guez, L., Guilyardi, E., Hauglustaine, D., Hourdin, F., Idelkadi, A., Ghattas, J., Joussaume, S., Kageyama, M., Krinner, G., Labetoulle, S., Lahellec, A., Lefebvre, M. P., Lefevre, F., Levy, C., Li, Z. X., Lloyd, J., Lott, F., Madec, G., Mancip, M., Marchand, M., Masson, S., Meurdesoif, Y., Mignot, J., Musat, I., Parouty, S., Polcher, J., Rio, C., Schulz, M., Swingedouw, D., Szopa, S., Talandier, C., Terray, P., Viovy, N., and Vuichard, N.: Climate change projections using the IPSL-CM5 Earth System Model: from CMIP3 to CMIP5, Clim. Dynam., 40, 2123-2165, doi:10.1007/s00382-012-1636-1, 2013.

Evensen, G.: The ensemble Kalman filter: Theoretical formulation and practical implementation, Ocean Dynam., 53, 343-367, doi:10.1007/s10236-003-0036-9, 2003.

Friedlingstein, P., Joel, G., Field, C. B., and Fung, I.: Toward an allocation scheme for global terrestrial carbon models, Glob. Change Biol., 5, 755-770, doi:10.1046/j.13652486.1999.00269.x, 1999.

Ghent, D., Kaduk, J., Remedios, J., and Balzter, H.: Data assimilation into land surface models: The implications for climate feedbacks, Int. J. Remote Sens., 3, 617-632, doi:10.1080/01431161.2010.517794, 2011.

Giering, R. and Kaminski, T.: Recipes for Adjoint Code Construction, ACM Trans. Math. Softw., 24, 437-474, doi:10.1145/293686.293695, 1998.

Gilbert, J. C. and LeMaréchal, C.: Some numerical experiments with variable-storage quasi Newton algorithms, Maths. Program, 45, 407-435, doi:10.1007/BF01589113, 1989.

Harrison, D. E., Chiodi, A. M., and Vecchi, G. A.: Effects of surface forcing on the seasonal cycle of the eastern equatorial Pacific, J. Mar. Res., 67, 701-729, doi:10.1357/002224009792006179, 2009.

Hascoët, L. and Pascual, V.: The Tapenade Automatic Differentiation tool: principles, model, and specification, Research Report Nro 7557. Project Team Tropics, INRIA, France, 2012.

Hascoet, L. and Pascual, V.: The Tapenade Automatic Differentiation tool: principles, model, and specification, ACM Transactions on Mathematical Software, Association for Computing Machinery, 39, doi:10.1145/2450153.2450158, 2013.

Huang, C., Li, X., and Lu, L.: Retrieving land surface temperature profile by assimilating MODIS LST products with ensemble Kalman filter. Cold and Arid Regions Environmental and Engineering Research Institute, CAS, Lanzhou, China, doi:10.1016/j.rse.2007.03.028, 2003.

Ide, K., Courtier, P., Ghil, M., and Lorenc, A.: Unified Notation for Data Assimilation: Operational, Sequential and Variational, Special Issue, J. Meteorol. Soc. Jpn., 75, 181-189, doi:10.1.1.47.2607, 1997.

Krinner, G., Viovy, N., Noblet-Ducoudre, N. de, Ogee, J., Polcher, J., Friedlingstein, P., Ciais, P., Sitch, S., and Prentice, I. C.: A dynamic global vegetation model for studies of the coupled atmosphere-biosphere system, Global Biogeochem. Cy., 19, 1, doi:10.1029/2003GB002199, 2005.

Kuppel, S., Peylin, P., Chevallier, F., Bacour, C., Maignan, F., and Richardson, A. D.: Constraining a global ecosystem model with multi-site eddy-covariance data, Biogeosciences, 9, 3757-3776, doi:10.5194/bg-9-3757-2012, 2012. 
Lahoz, W. and Khattatov, B.: Data Assimilation Making Sense of Observations, Springer Editions, 2010.

Le Dimet, F.-X. and Talagrand, O.: Variational Algorithms for Analysis and Assimilation of Meteorological Observations: Theoretical Aspects, Dynamic Meteorology and Oceanography, 38, 97110, doi:10.1111/j.1600-0870.1986.tb00459.x, 1986.

Nardi, L., Sorror, C., Badran, F., and Thiria, S.: YAO: A Software for Variational Data Assimilation Using Numerical Model, Computational Science and its Applications - ICCSA 2009, International Conference, 5593, 2, 621-636, 2009.

Pipunic, R. C., Walker, J. P., and Western, A.: Assimilation of remotely sensed data for improved latent and sensible heat flux prediction: A comparative synthetic study, 19th International Congress on Modelling and Simulation, Perth, Australia, doi:10.1016/j.rse.2007.02.038, 2008.

Reichle, R., Kumar, S., Mahanama, S., Koster, R. D., and Liu, Q.: Assimilation of satellite-derived skin temperature observations into land surface models, J. Hydrometeorol., 11, 1103-1122, doi:10.1175/2010JHM1262.1, 2010.

Ridler, M., Sandholt, I., Butts, M., Lerer, S., Mougin, E., Timouk, F., Kergoat, L., and Madsen, H.: Calibrating a soil-vegetation-atmosphere transfer model with remote sensing estimates of surface temperature and soil surface moisture in a semi-arid environment, J. Hydrol., 436-437, 1-12, doi:10.1016/j.jhydrol.2012.01.047, 2012.
Robert, C., Blayo, E., and Verron, J.: Comparison of reduced-order, sequential and variational data assimilation methods in the tropical Pacific Ocean, Ocean Dynam., 56, 624-633, 2007.

Saltelli, A.: Sensitivity Analysis, John Wiley \& Sons Edition, United States of America, doi:10.1007/s10236-006-0079-9, 2008.

Sitch, S., Smith, B., Prentice, I. C., Arneth, A., Bondeau, A., Cramer, W., Kaplan, J. O., Levis, S., Lucht, W., Sykes, M. T., Thonicke, K., and Venevsky, S.: Evaluation of ecosystem dynamics, plant geography and terrestrial carbon cycling in the LPJ dynamic global vegetation model, Glob. Change Biol., 9, 161-185, doi:10.1175/15257541(2002)003<0728:EVEKFF>2.0.CO;2, 2003.

Svendsen, H.: The effect of clear sky radiation on crop surface temperature determined by thermal thermometry, Agr. Forest Meteorol., 50, 239-243, doi:10.1016/0168-1923(90)90057-D, 1990.

Talagrand, O.: The use of adjoint equations in numerical modeling of the atmospheric circulation, Automatic Differentiation of Algorithms: Theory, Implementation, and Application, edited by: Griewank, A. and Corliess, G., SIAM, 169-180, 1991.

Verbeeck, H., Peylin, P., Bacour, C., Bonal, D., Steppe, K., and Ciais, P.: Seasonal patterns of $\mathrm{CO}_{2}$ fluxes in Amazon forests: $\mathrm{Fu}-$ sion of eddy covariance data and the ORCHIDEE model, J. Geophys. Res., 116, GO2018, doi:10.1029/2010JG001544, 2001. 